\title{
CRITERIOS PARA LA CONSERVACIÓN Y REVALORIZACIÓN DEL URBANISMO COLONIAL HISPANOAMERICANO: ESTUDIO DE CASO ${ }^{* *}$
}

\author{
CRITERIA FOR PRESERVATION AND VALUE ENHANCEMENT OF SPANISH-AMERICAN \\ COLONIAL URBANISM: A CASE STUDY \\ CARLOS QUEVEDO ROJAS $S^{(\star)}$
}

Fecha de recepción: 30 de agosto de 2016

Fecha de aprobación: 26 de noviembre de 2016

\begin{abstract}
RESUMEN
Las ilaciones entre España y América en el ámbito urbanístico, en tanto soporte de un diálogo cultural continuo llevado a cabo durante siglos, deja una impronta marcada como patrimonio que aún se sostiene como legado de ultramar. Las experiencias urbanizadoras llevadas a cabo en lo que Hardoy llamaba "modelo clásico de ciudad hispanoamericana", el continuo intercambio cultural, y el vínculo entre las ordenanzas y los fueros que marcaban sus directrices son claros exponentes de la fuerte influencia americana sobre las urbes peninsulares y viceversa, un diálogo continuo llevado a cabo desde ambos lados del Atlántico. Esta 'identidad urbana', que abarca también lo intangible, persiste hasta la actualidad como un elemento común que forma la base sobre la que se van amoldando los fragmentos de un complejo mosaico (sociedades dependientes, yuxtaposiciones culturales, etc.). La conservación de estas estructuras urbanas como señas de identidad cultural, pasando por el reconocimiento de los elementos patrimoniales existentes, es una premisa para establecer criterios para la puesta en valor de los mismos.
\end{abstract}

\section{PALABRAS CLAVE}

Colonización, Hispanoamérica, urbanismo

\begin{abstract}
The relationship between Spain and America in the urban-planning discipline, inasmuch as it supports an ongoing cultural dialog throughout the centuries, leaves a stamp, marked as heritage, that still resists as an overseas legacy. The urban-planning experiences carried out in what Hardoy called a "classic model of Spanish-American city", the continuous cultural exchange and the link between the ordinances and charters that marked their guidelines are clear exponents of the strong influence America had on peninsular cities, and vice versa. It was a continuous dialog carried out from both sides of the Atlantic Ocean. This 'urban identity', which also includes what is intangible, persists up to date as a common element that forms the base on which the fragment of a complex mosaic are molded (dependent societies, cultural juxtapositions, etc.). The preservation of these urban structures as signs of a cultural identity, after the recognition of the existing heritage elements, is a premise for the establishment of criteria for their value enhancement.
\end{abstract}

\section{KEYWORDS}

Colonization, Spanish America, urbanism

${ }^{*}$ ) El presente artículo forma parte de la tesis titulada Approach to the ideal concept of urban planning in the 18th century: colonial settlements in Andalusia, elaborada para optar por el grado de doctor en Arquitectura (2014-actualidad), la cual se está desarrollando en régimen de cotutela, dirigida por D. Antonio Tejedor Cabrera, director del Instituto Universitario de Ciencias de la Construcción por la Universidad de Sevilla (España), y por D. Alberto Ferlenga, excelentísimo rector del Istituto Universitario di Architettura di Venezia (IUAV), Italia.

(**) Arquitecto por la E.T.S.A. de Sevilla, máster en Arquitectura y Patrimonio Histórico (Universidad de Sevilla), máster en Historia del Arte: investigación y tutela del patrimonio histórico (Universidad de Granada), Specialista in beni architettonici e del paesaggio per lo studio ed il restauro dei monumenti (Universitá "La Sapienza" di Roma) y doctorando internacional en Arquitectura (IUAV di Venezia y Universidad de Sevilla). Docente en la Escuela de Arte y Diseño de Cádiz. Premio nacional de urbanismo "Ricardo Santos Díez", premio Architizer A+ Awards en Architecture+Preservation, seleccionado premio Internacional de Paisaje y Bienal "Rosa Barba", catalogado premio Arquia Próxima y seleccionado en Factual de la Fundación de Arquitectura Contemporánea para jóvenes arquitectos. Contacto: carquev@hotmail.com 


\section{Introducción a las ilaciones urbanas transatlánticas}

Las nuevas formas urbanas impuestas en América desde el siglo XVI tuvieron poco que ver con el diagrama tradicional de la ciudad medieval que aún prevalecía en ese momento en el conjunto de la Península Ibérica. Más bien parecían provenir de los grandes tratados de arquitectura del Renacimiento (aspiración al orden geométrico y la racionalidad; unidad, planificación y orden riguroso), ser indagaciones en torno al concepto de 'ciudad ideal' bajo los preceptos de Vitruvio o de Vasari.

En cierta manera, el proceso de identificación y de mimetismo que facilitó la transmisión de un modelo español estuvo más cerca del campo de lo intangible (potestades urbanas, cultura ciudadana, ocupación impositiva) que al de la planificación, en el concepto de identificación urbana, jugando con la ambigüedad del mismo. De ahí que en ambas partes del Atlántico las ciudades tengan cierta relación de "identidad urbana" que puede ser percibida como una reivindicación de la misma, y que no es una paradoja para las ciudades españolas que cuentan con similar trazado urbano (Musset et al., 1997, p. 14).

En cierto sentido, la América de principios del siglo XVI era una utopía. Teorías y prácticas de la ciudad se mezclaron para dar forma a paisajes urbanos comunes a todos los territorios de la Corona. Esta es la originalidad y la paradoja de la ciudad española en América: lo idéntico crea la identidad. Lo mismo va a ocurrir con las poblaciones de colonización en la Península siglos después.

En relación a tal época colonial es necesario tener en cuenta las lógicas de formación y desarrollo de las ciudades sobre los asentamientos naturales (Lima o Trujillo) o sobre poblaciones indígenas (Cuzco o Ciudad de México). En este último caso casi siempre se ejecutaron los nuevos asentamientos sin tomar en cuenta el entramado precolombino a existente. Son importantes en este sentido las ordenanzas que marcan las directrices sobre cómo crear estos modelos de urbe y su relación con las ordenanzas urbanísticas peninsulares.

Sin duda, la tarea de colonización en América estaba condicionada a un modelo de ocupación del territorio y un modelo de asentamiento en el cual el urbanismo cuenta con un rol prioritario. El impulso expansivo se realizó con gran rapidez, casi completándose a mitad del siglo XVI. En las colonias hispanoamericanas no existió un patrón explícito anterior a las mismas, sino que se trata más bien de la convergencia de ciertas características modélicas precedentes, asumidas implícitamente.

Comienzan así a crearse las distintas formaciones urbanas: primero en las Islas Mayores del Caribe (Santo Domingo, Cuba y Puerto Rico), con un carácter semirregular; luego en el propio continente (Veracruz y Panamá) en 1519 con un trazado regular de calles y plazas en torno a una plaza central; posteriormente, influenciado por la Ordenanza de 1523, surge como ejemplo la Ciudad de México (asentada sobre la ciudad precolombina de Tenochtitlan); y en una última fase (a partir de 1535) se consolida el ejemplo más generalizado del "modelo clásico de ciudad hispanoamericana" (Hardoy, 1972, p. 73), Lima (Figuras 1, 2, 3 y 4).

De forma casi coetánea a las colonias americanas, hemos de citar en la Península Ibérica procesos fundacionales en la región andaluza, tales como Puerto Real, Mancha Real o Santa Fe, que siguen el mismo esquema de trazado geométrico en damero. De esta forma el urbanismo adquiere un afán de racionalidad como signo de una modernidad (Gutiérrez et al., 1995).

Es posible observar el ejemplo de Lima como máxima evolución urbana y "modelo" para otras urbes hispanoamericanas. Cada manzana o cuadra era un cuadrado perfecto de 450 pies y estaba dividida en cuatro solares, mientras que las calles tenían 

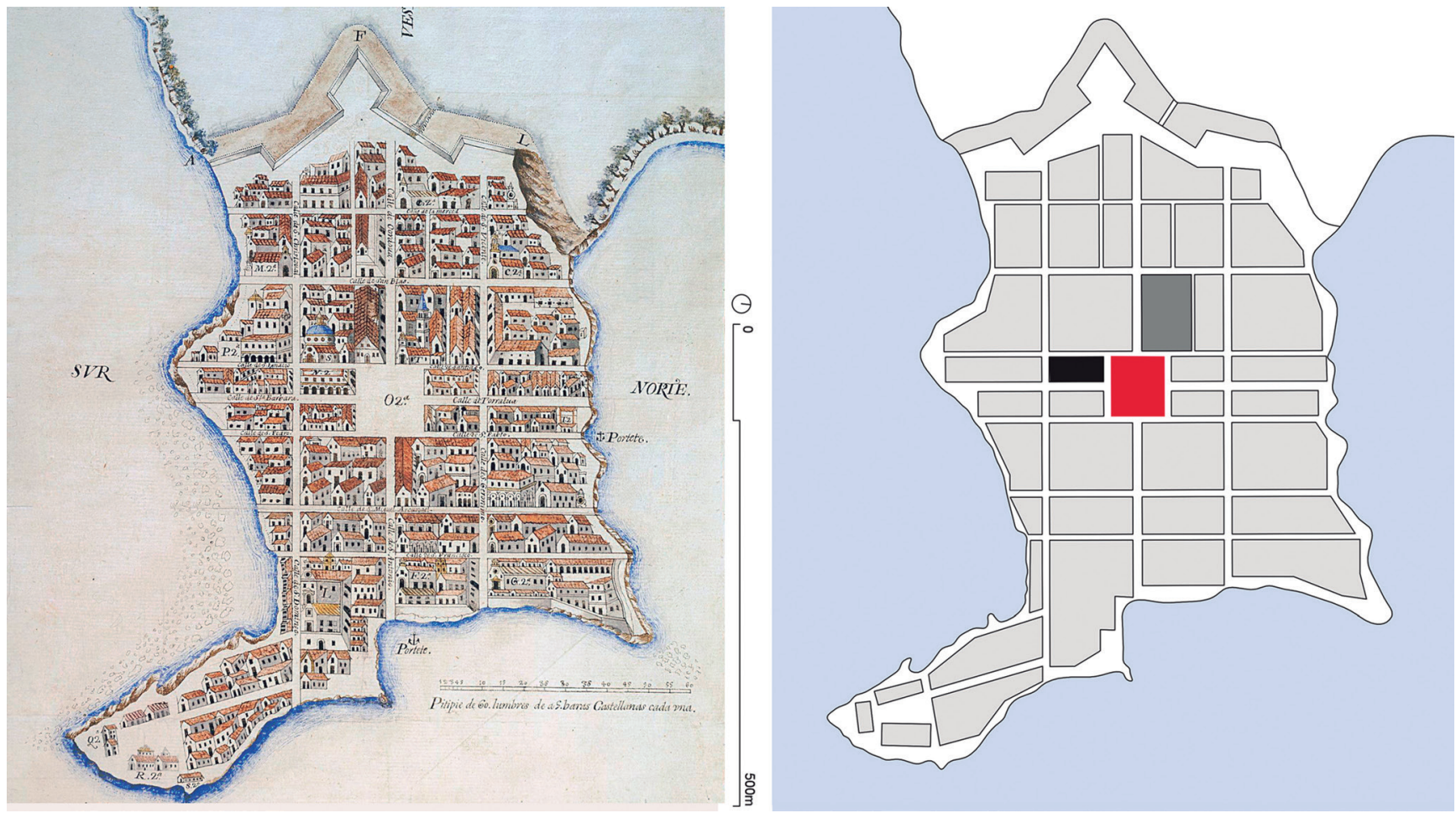

Figura 1. Plano de la Ciudad de Panamá según ha de quedar en el sitio donde se está mudando, 1673 Fuente: Sevilla: Archivo General de Indias. Sign. MP-PANAMA, 84. Esquema, elaboración propia (Rojo, espacio público central; Negro, poder civil; Gris, poder religioso), 2016.
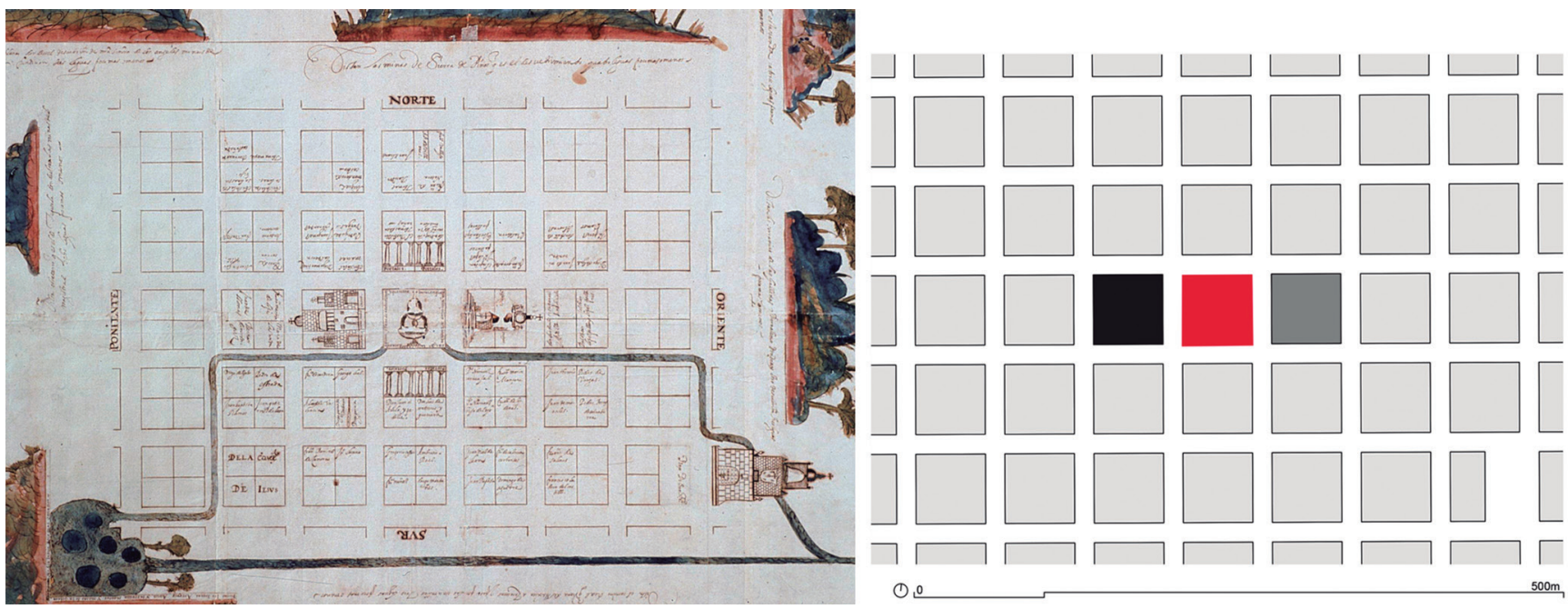

O. 0

Figura 2. Planta de la nueva población que se ha de hacer en los llanos de la Goleta, a cuatro leguas de las minas de Nuestra Señora de la Concepción de Sierra de Pinos (Jalisco), 1603

Fuente: Sevilla: Archivo General de Indias. Sign. MP-MEXICO, 51. Elaboración propia, 2016. 
devenir Vol. 3, N6, JULIO-DICIEMBRE 2016, Pp. 9-30 - Estudios I ISSN 2312-7570

UNIVERSIDAD NACIONAL DE INGENIERÍA, LIMA
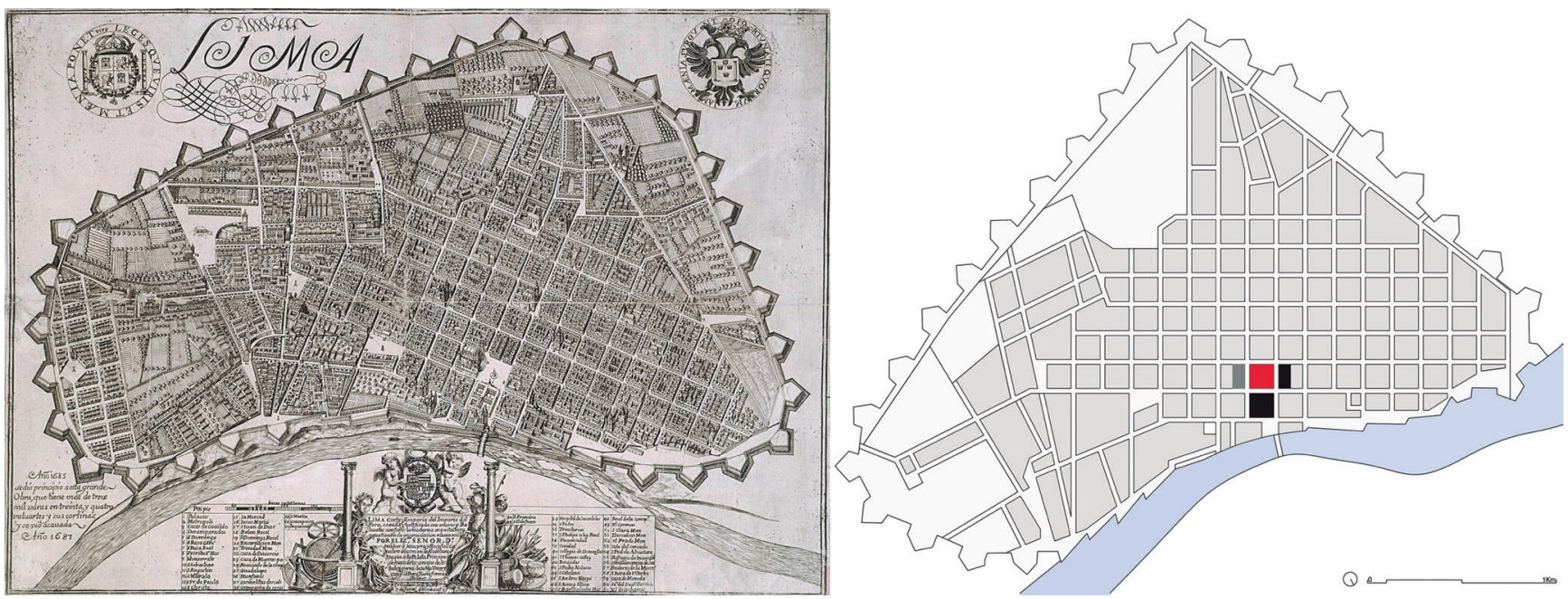

Figura 3. Lima, Ciudad de los Reyes, Corte y Emporio del Imperio Peruano (1687)

Fuente: Sevilla: Archivo General de Indias. Sign. MP-PERU_CHILE, 13. “Fr. P. Nolasco Ord. B. M. de Merced, delineauit et sculpsit". Elaboración propia, Carlos Quevedo, 2016.

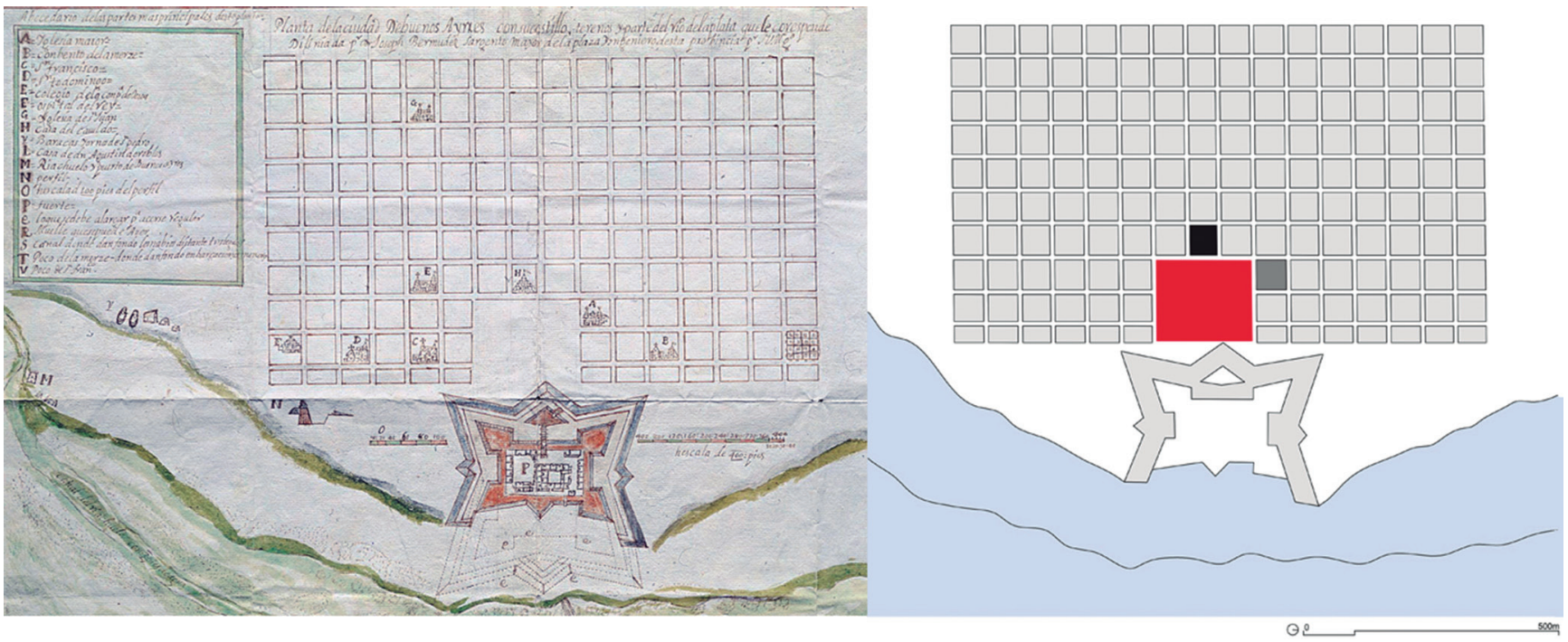

Figura 4. Planta de la ciudad de Buenos Ayres con su castillo, terenos [sic] y parte del Río de la Plata que le corresponde, 1708

Fuente: Sevilla: Archivo General de Indias. Sign. MP-BUENOS AIRES, 38.“Diliniada por D. Joseph Bermúdez, Sargento Mayor de la plaza y ingeniero desta provincia por Su Magestad". Elaboración propia, 2016.

40 pies de ancho. Las 13 por 9 calles albergaban una cuadrícula que constaba de 117 manzanas. Lima pasó a ser en el siglo XVI el centro del imperio español en Sudamérica y el equivalente a México en Mesoamérica. En el Perú colonial el poder estaba concentrado en la Plaza Mayor y sus alrededores (casa del gobierno, cabildo e iglesia). La plaza se desplaza en este caso hacia el río.

En dibujos de la época como los que representa Poma de Ayala (Guamán, s. XVII) es posible apreciar la vida en el corazón de esta plaza central limeña como espacio articulador y común de todo lo que rodea, y que permiten también observar las confluencias de ambas tradiciones, la autóctona y la europea (Figura 5). 
Las relaciones urbanas iberoamericanas tienen correspondencia en ambos sentidos. Por ejemplo, en torno a la reconstrucción de Lima tras su terremoto en 1746, se plantearon y discutieron diversas propuestas de acuerdo a las nuevas directrices modernas que surgían en Europa y que, debido a los límites presupuestarios, impedían la magnificencia de tan ardua empresa (Walker, 2012). Existen notables y lógicas distinciones de configuración física a ambos lados del Atlántico, sobre todo en las ciudades portuarias hispanoamericanas. Principalmente se puede apreciar la necesidad de colocar elementos de defensa a mediados del s. XVI (La Habana, Cartagena de Indias, Portobelo, Panamá, Lima, etc.) que delimiten los bordes de las ciudades y restrinjan la apertura de la retícula hacia su entorno (Terán, 2001).

También es obligatorio remarcar la evolución urbana de estas colonias americanas y es que, si bien se produce un fuerte impulso de expansión y ejecución en el s. XVI, este decae en el s. XVII. Durante el s. XVIII, los núcleos urbanos se siguen desarrollando en las colonias americanas, con la diferencia de que se realiza mayor número de subdivisiones en las parcelaciones interiores de las manzanas, de manera semejante a las peninsulares, manteniendo la retícula. También el 'modelo clásico de ciudad hispanoamericano' va evolucionando, con calles que salen por el centro de los lados que obligan geométricamente a que las manzanas sean rectangulares, o incorporación de un mayor número de espacios libres entrando por el centro en algunos casos, que rompen la homogeneidad de la cuadrícula clásica.

Se puede ya, por tanto, identificar características comunes entre las colonizaciones hispanoamericanas y peninsulares posteriores (mostramos esquemas comparativos de distintos casos):

- Trazado geométrico: calles rectas que se cortan formando retículas ortogonales rectangulares o cuadradas, diseño que se siguió en la mayor parte de las colonias hispanoamericanas

- Transformación de una manzana central libre en el espacio público principal y corazón de la urbe, el núcleo estructural básico desde donde se genera y articula la ciudad: la plaza mayor, centro geométrico, vital y simbólico. Cuando la ciudad se asienta cerca de un río o ribera, este núcleo se suele desplazar junto al mismo. Como espacio central es lugar de encuentro social, oficial, comercial, etc.

- Ubicación de los edificios de poder y de la religión en torno al espacio central: casa de cabildo, catedral/iglesia principal, palacios, administración

- Parcelación interior homogénea y equitativa de cada manzana

- Prolongación de la ciudad, que sirve de soporte a la extensión de la ciudad en todas sus direcciones; soporte para un desarrollo isótropo.

- Correspondencia con una imagen de urbe baja, poco edificada, en la cual los inmuebles ocupan solo pequeñas porciones de parcelas muy grandes. El resto queda libre para huertos y tenencias de animales, y las demás alineaciones exteriores se cierran con tapias, que posteriormente evolucionan y se colmatan.

Marchena Fernández (2001) afirma que en las Nuevas Poblaciones "las calles seguirían el modelo americano, con traza de damero, calles a cordel creándose cuadras regulares y del mismo tamaño, y una plaza en el centro donde se situarían la iglesia, el cabildo y los edificios de las principales instituciones" (p. 63) (Figura 6).

Pero es interesante también que, de manera recíproca, la llustración europea (hasta finales del s. XIX las colonias americanas siguen estando bajo dominio español) influye en las urbes coloniales americanas: se incorporan infraestructuras de saneamiento y se realizan mejoras en el abastecimiento de aguas, así como en la dotación de espacios

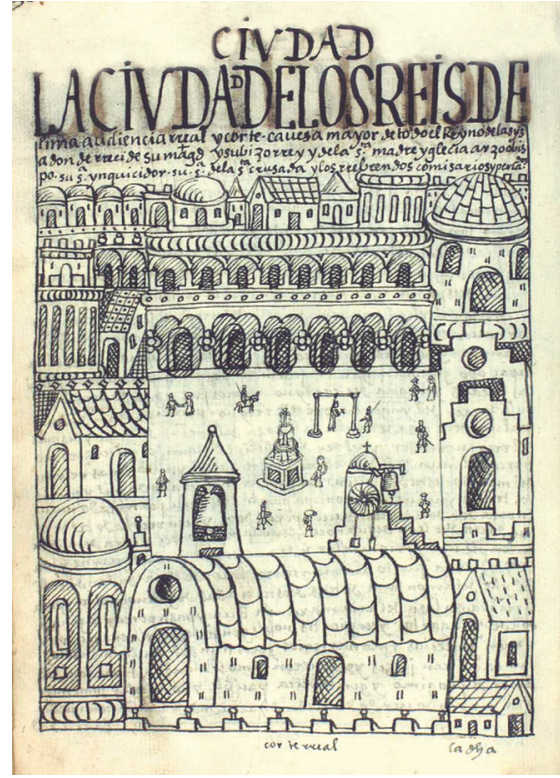

Figura 5. LA CIVDAD DE LOS REIS DE Lima, audiencia rreal y corte, cauesa mayor de todo el rreyno de las Yndias (...), 1615

Fuente: Copenhague: Det Kongelige Bibliotek. La Nueva Crónica del Buen Gobierno del peruano Felipe Guamán Poma de Ayala.1031 [1039] 


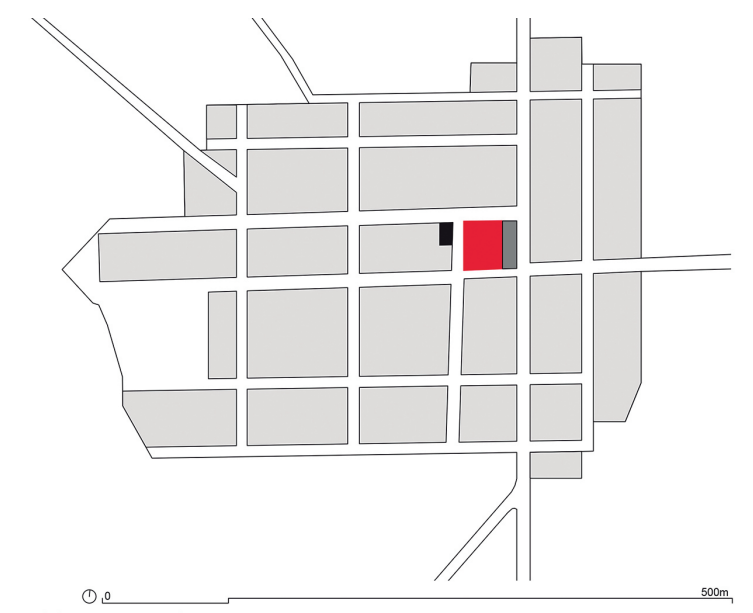

Aldeaquemada

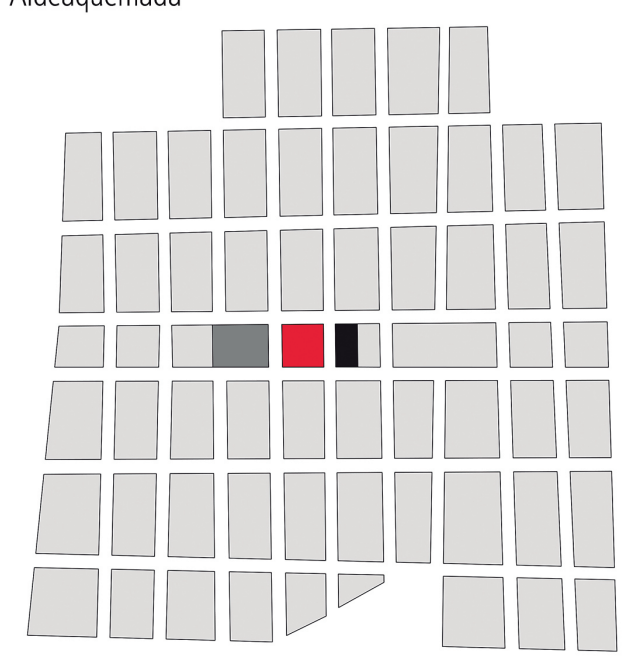

.0

Prado del Rey

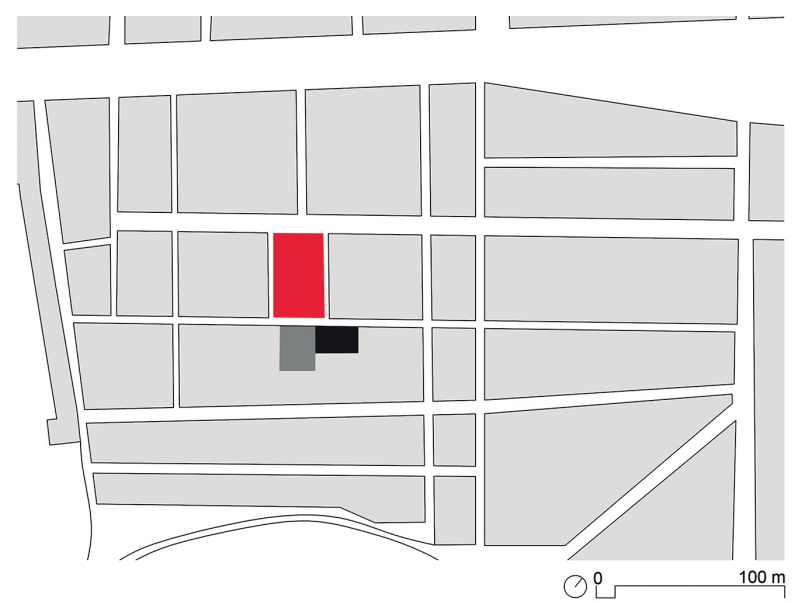

Guarromán

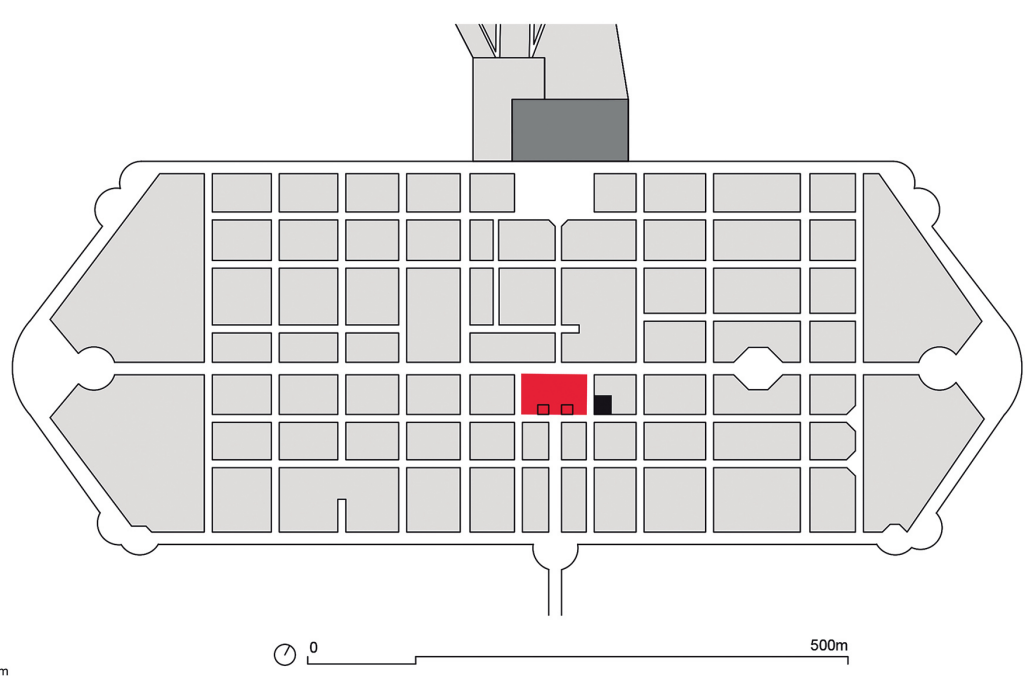

La Carolina
Figura 6. Esquemas de algunas Nuevas Poblaciones de Colonización de Andalucía del siglo XVIII en la actualidad

Fuente: Elaboración propia, 2016. verdes, mediante la incorporación de alamedas y paseos perimetrales. En esta segunda fase de "ciudad pensada" (Terán, 2001, p. 15), el sistema de parcelación aumenta la compacidad y la intensidad de ocupación de las manzanas, lo cual produce la deshomogeneización de la cuadrícula.

Mediante este diálogo cultural, las poblaciones de colonización peninsulares influyeron directamente sobre casos específicos en América. Por ejemplo, la fundación de asentamientos españoles campesinos y de comercio en Puerto Rico en esa época (tales como Anguilas, San Carlos y Almuradiel), que fueron propugnadas por el conde de Floridablanca, se relacionan con el ejemplo andaluz (Mattos, 1987).

En este sentido la intersección entre territorialidad urbana e imaginario utópico es central no solo para el modelo implementado durante la colonización europea en Hispanoamérica, sino para la consumación de proyectos modernizadores que recorrieron el continente los procesos de independencia (Heffes, 2013).

Un claro ejemplo de intercambio cultural transatlántico en el que directamente se ve reflejado el sistema de trazado urbano en las colonias peninsulares se encuentra en la figura del criollo D. Pablo de Olavide. El limeño fue el promotor de las Nuevas Pobla- 
ciones de Colonización en Sierra Morena y Andalucía a finales del siglo XVIII, el mejor ejemplo de urbanismo ilustrado en la Península (Chueca, 1970).

Olavide tuvo una participación activa en la reconstrucción de Lima tras el terremoto de 1746; se encargó de la supervisión del proceso de reconstrucción de cada calle: “El Sr. D. Pablo de Olavide, desde la puerta principal de la Encarnación hasta la puerta de su casas y desde la esquina de Núñez hasta la puerta falsa de la Encarnación"1.

El terremoto de Lima le dio oportunidad de manifestar otras aptitudes que revelan su personalidad: la capacidad de organizar amplias empresas, así como de plantear y resolver cuestiones ideológicas generales, y llevarlas a praxis en elementos concretos (Figura 7).

Las raíces americanas de Olavide, por tanto, se pueden percibir o descubrir en esa actitud suya de desasimiento de prejuicios y ataduras con lo establecido y consagrado que aflora en distintos momentos de su vida. Su justificada estrategia evitó la destrucción de una tradición, pero su tarea consistió en injertar nuevas ramas, en introducir una distinta actitud acorde al orden de ideas nuevas con el progreso de la cultura en otros lugares de Europa, especialmente Francia e Inglaterra.

Otra gran influencia limeña sobre Olavide fue su compañero de trabajo en la Real Audiencia de Lima, el Oidor Pedro Joseph Bravo de Lagunas, que trabajó con él en la reedificación de Lima tras el terremoto (Lohmann, 1974). Bravo fue brillante defensor de la causa peruana por la mejora y reforma de la agricultura y el comercio. Por tanto, su Informe sobre la Ley Agraria (principal referente de la reforma agraria y económica que fue la base legislativa para la formación de las Nuevas Poblaciones andaluzas), que posteriormente copiaría Jovellanos, es trabajo en el que se ve la influencia de su origen criollo limeño. De la misma forma, Miguel de Gijón y León, comerciante acaudalado criollo de Quito, se desempeñó como subdelegado de las Nuevas Poblaciones (Marchena, 2001). Fue él quien proporcionó los datos a Diderot para confeccionar la biografía de Olavide que sirvió para consagrarlo como liberal y reformista en Europa. También los criollos Juan Miguel Camaño y Goicoechea fueron colaboradores del superintendente.

También, en ese sentido, D. Bernardo Darquea, que fue secretario de la Superintendencia en las mismas Nuevas Poblaciones, siguió las pautas de Olavide al reconstruir la ciudad de Riobamba (Ecuador). También Bartolomé Fammi, delineante en Sierra Morena, fue nombrado maestro arquitecto para Puerto Rico, donde hizo grandes obras (Mattos, 2004).

Es inevitable, en el mismo sentido, remarcar el paralelismo de las Nuevas Poblaciones andaluzas, como ejemplos prácticos de aplicación de las teorías ilustradas, con los casos que tuvieron lugar en la América, ya independizada a mediados del s. XIX. Por ejemplo, la ciudad utópica de Argirópolis que, desde un punto de vista geopolítico, propone el presidente argentino Domingo F. Sarmiento para ubicarla en la isla Martín García, como vehículo de civilización y forma de acabar con los "campos incultos", transformar el "vacío" americano en espacios para los "pueblos civilizados" (Heffes, 2013, p. 13). O en la propuesta de J. Bautista Alberdi en sus "Bases", que impulsa asentamientos humanos en zonas desiertas como solución a la emigración rural de Europa (al igual que a las Nuevas Poblaciones andaluzas inmigraron colonos de Centroeuropa para ocupar y explotar los baldíos de Sierra Morena).

Una entidad común al urbanismo español en el siglo XVIII son las ideas de centralización del poder absolutista orientadas a tener un mayor control del gobierno no solo en la Península, sino también en todas sus colonias (incluyendo América y el sur de Italia), lo que conlleva plantear ordenanzas o modos de ejecución básicos y estandarizados en la evolución urbana de sus ciudades.

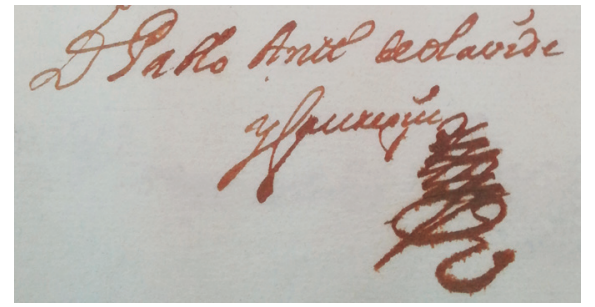

Figura 7. Firma de Pablo de Olavide, 11 de noviembre de 1748

Fuente: Lima: Archivo General de la Nación. Catálogo Sección Contencioso (SO-CO 211-1865). Pleito de las hermanas Aulestia contra Pablo de Olavide, p. 42.

1. Archivo General de Indias, Lima 511: Expedientes sobre la reconstrucción de Lima, 1748 
devenir Vol. 3, №6, JULIO-DICIEMBRE 2016, Pp. 9-30 - Estudios I ISSN 2312-7570

UNIVERSIDAD NACIONAL DE INGENIERÍ, LIMA

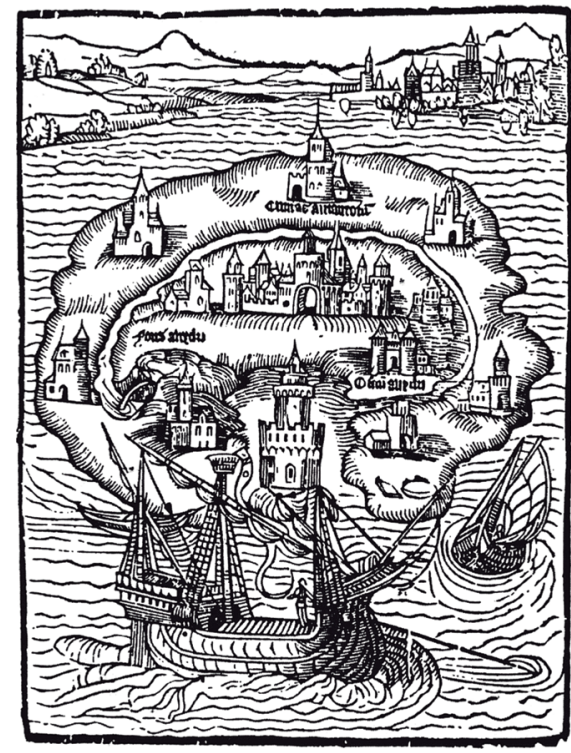

Figura 8. llustración de la primera edición de Utopía editada en Londres Fuente: Thomas More, 1516.
Existen ya precedentes jurídicos desde el siglo XIII como son los fueros, cartas pueblas y partidas que se redactan durante la reconquista de las ciudades árabes en la Península, que se marcan las directrices de los nuevos asentamientos, ya fueran existentes o de nueva planta. Ejemplo de ello es el fuero Alfonsino (1329). Sin embargo, la ciudad colonial hispanoamericana, más allá de superficiales analogías, no tiene antecedentes iguales ni en Europa ni en América precolombina (Terán, 2001).

Por ello son importantes como experiencias urbanizadoras previas sobre las colonias hispanoamericanas las normativas urbanísticas como la que se materializó en la Instrucción a Pedrarias Dávila en $1513^{2}$, la ordenanza de Carlos V de $1523^{3}$ y, especialmente, las ordenanzas de población de Felipe II, de 15734. Posteriormente la Recopilación de las Leyes de Indias, editada en 1681, recoge en su Libro IV, títulos 5 a 8 y 12, la posición oficial de la Corona en asuntos urbanos asumiendo las dos ordenanzas anteriores.

Incluso en el siglo XVIII, en una real ordenanza promulgada el 11 de abril 1738 en respuesta a una denuncia presentada por el Consejo de la ciudad de Lima, Felipe V especifica que las normas adoptadas para formar los municipios americanos tenían que seguir aquellas que se observaban en las ciudades andaluzas.

Estas "Ordenanzas de Descubrimiento, Nueva Poblaçion y Pacificaçion" se pueden entender como el primer reglamento de urbanística y de arquitectura escrita de la edad moderna. "El texto de esta ley es en parte un compendio de las nociones teóricas adquiridas en la cultura del tiempo, y en parte el resumen de una experiencia consolidada: por lo tanto describe un modelo individualizado para la convergencia sobre el terreno operativo" (Benévolo, 1979). Se propone por primera vez la institucionalización de la aportación de la cultura arquitectónica al complejo de las condiciones vinculantes. Maduran en el mismo ámbito contrarreformista con toda la acción militar y política de la Corona española y de la Iglesia italiana.

El articulado establece la importancia de la plaza mayor latinoamericana. Los argumentos arquitectónicos que se introducen son relativos a la localización, a la formación y al uso. Además se informa sobre cómo y por qué es el primer elemento generador del trazado urbano de la colonia. Su ubicación depende de sus condicionantes geográficos. También hace referencia a la forma de este espacio (cuadrada o rectangular). Se establece en ese sentido también la relación entre la geometría de la plaza y la del trazado, así como la relación entre el monumento urbano y la formación del tejido. El tema se desarrolla a través de dos cuestiones modales: la ubicación como sistema clasificatorio de la jerarquía urbana y el retroceso como condición de subordinación del detalle arquitectónico a las reglas generales del trazado.

La repetición del modelo fundacional se localiza en este punto como garantía de belleza, orientada a construir un paisaje territorial de clara impronta imperial, importante cuestión de la gestión del territorio extraurbano. La ciudad americana resulta tanto desde el ámbito práctico como desde el teórico una "ciudad infinita", que se puede administrar a partir de la relación del territorio circundante bajo criterios de continuidad física y proyectual. También se afronta la cuestión del valor de la arquitectura en la construcción del paisaje urbano, tanto desde el valor compositivo como desde el valor representativo.

\footnotetext{
2. Publicada en Fernández de Navarrete, Martín. 1943-48. Colección de los viajes y descubrimientos que hicieron por mar los españoles desde fines del siglo XV. 5 Vols. Madrid, España: Biblioteca de autores Españoles.

3. Ley Primera del Título Séptimo del Libro Cuarto de la Recopilación de las Leyes de los Reynos de las Indias mandadas imprimir y publicar por la Magestad Católica del Rey don Carlos II nuestro señor, 1681, titulada Que las "nuevas poblaciones se funden con las calidades de esta Ley", firmada por Carlos I en 1523. Madrid, España: publicada por lulian de Paredes.

4. Ordenanza de población. "El Orden q sea de thener en descubrir y poblar" Archivo General de Indias. Publicadas en El Escorial, firmada por Felipe II el 13 de julio de 1573.
} 


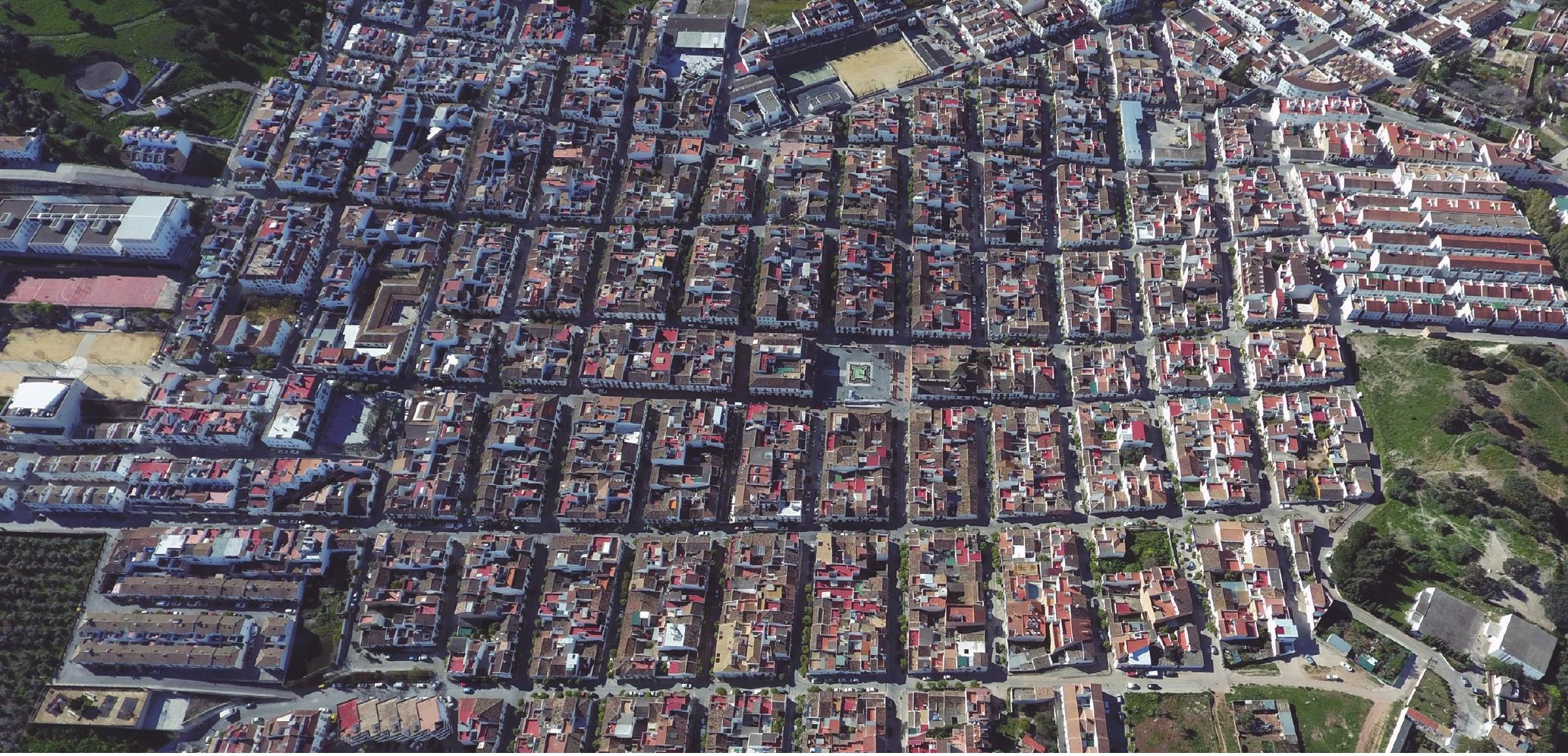

El fuero de las Poblaciones de Colonización de Sierra Morena y Andalucía , de 1767, con clara influencia de la experiencia urbanizadora previa en América, es el reglamento que establece las condiciones que debían tener las nuevas poblaciones; el número de casas de que habrían de constar, la cantidad de tierra a repartir; las distancias entre poblaciones; la constitución de las feligresías; los instrumentos de labranza; la distribución de animales, molinos, escuelas, etc.

Hemos de destacar los contenidos en los que se establecen influencias directas con respecto a las ordenanzas anteriores y que se traducen en similitudes en su configuración física:

- Elección del lugar basándose en sus condicionantes geográficos

- Reparto equitativo de tierras

- Organización y jerarquía entre los núcleos de población

- Centralización del poder civil y religioso en la urbe

- Regulación de la propiedad

- Establecimiento de una base normativa ante la creación de una serie de asentamientos para que se produzcan de una forma ordenada, justa, planificada, racional y equilibrada

\section{Estudio de caso: criterios para la valorización y conservación de los ele- mentos formales existentes del urbanismo colonial}

\section{Premisas}

Desde un punto de vista urbanístico, es en el propio proyecto inicial de la empresa colonizadora donde se van interponiendo las pautas, objetivos y estrategias sobre las que se va a actuar. Bajo la influencia de la teoría ilustrada, se actúa sobre una realidad física en un territorio concreto, con unos condicionantes sociopolíticos y económicos complejos y que provoca la propia evolución de dichos núcleos y de las infraestructuras que cosen el territorio a lo largo del tiempo. De aquí surge la inevitable cuestión: ¿qué queda realmente del concepto del "ideal urbano" de las colonizaciones en la actualidad? Se puede realizar el análisis del sistema desde tres escalas de trabajo diversas: territorial, urbana y arquitectónica (Figura 8).

Figura 9. Fotografía urbana actual del núcleo urbano de Prado del Rey (Cádiz, España)

Fuente: Francisco Chacón Martínez, 2015. 
devenir Vol. 3, Nº, JULIO-DICIEMBRE 2016, PP. 9-30 - Estudios I ISSN 2312-7570

UNIVERSIDAD NACIONAL DE INGENIERÍA, LIMA
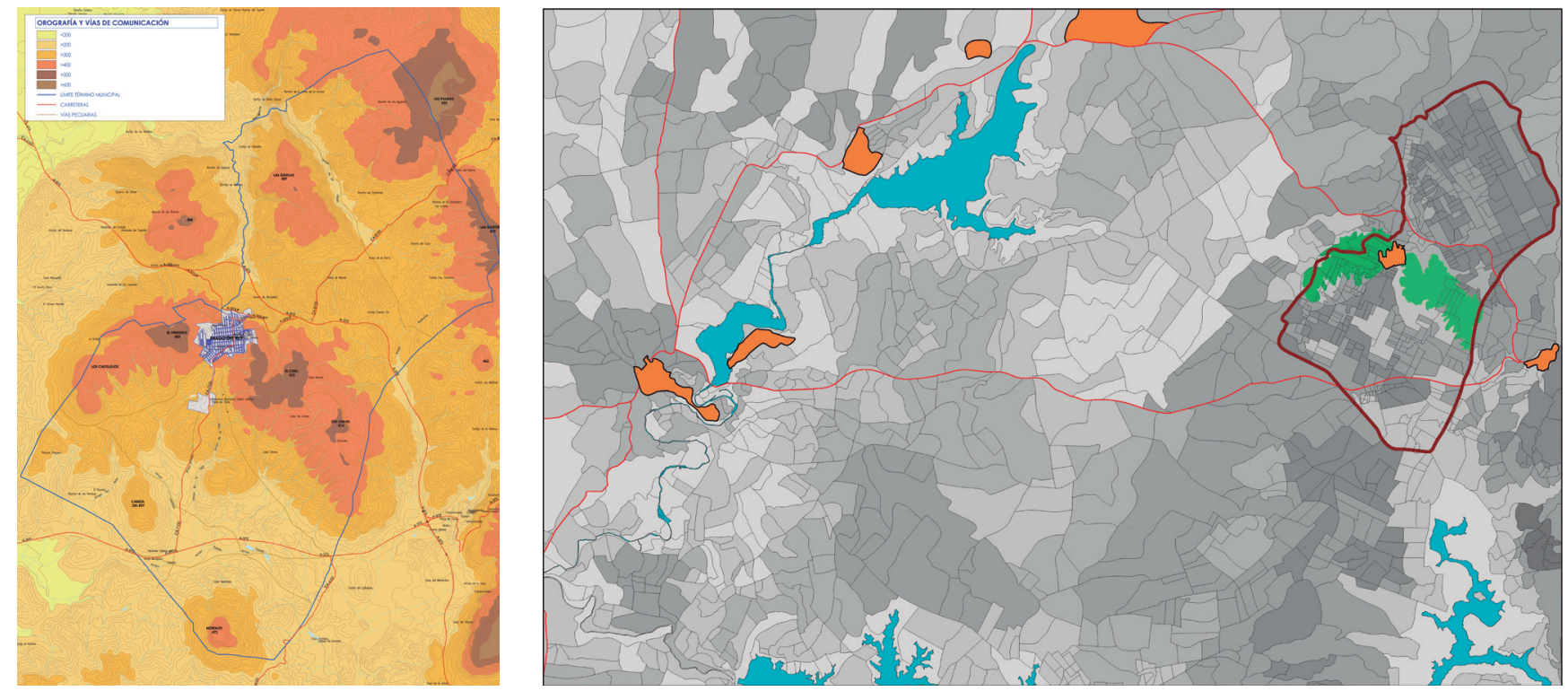

Figura 10. Orografía y ubicación del término municipal de Prado del Rey

Fuente: Elaboración propia, 2012.

Figura 11. Parcelario fundacional minifundista de Prado del Rey en su contexto territorial actual

Fuente: Elaboración propia, a partir de la oficina virtual del catastro, 2012.

Figura 12. Esquema gráfico sobre planimetría fundacional de la Dehesa de Almajar en Prado del Rey

Fuente: Papeles del Conde de Águila, Tomo 56, $18^{\circ}$. Archivo Municipal de Sevilla, 1768

Figura 13. Esquema gráfico comparativo sobre planimetría catastral actual de la Dehesa de Almajar

Fuente: Elaboración propia, a partir de plano catastral actual, 2015.
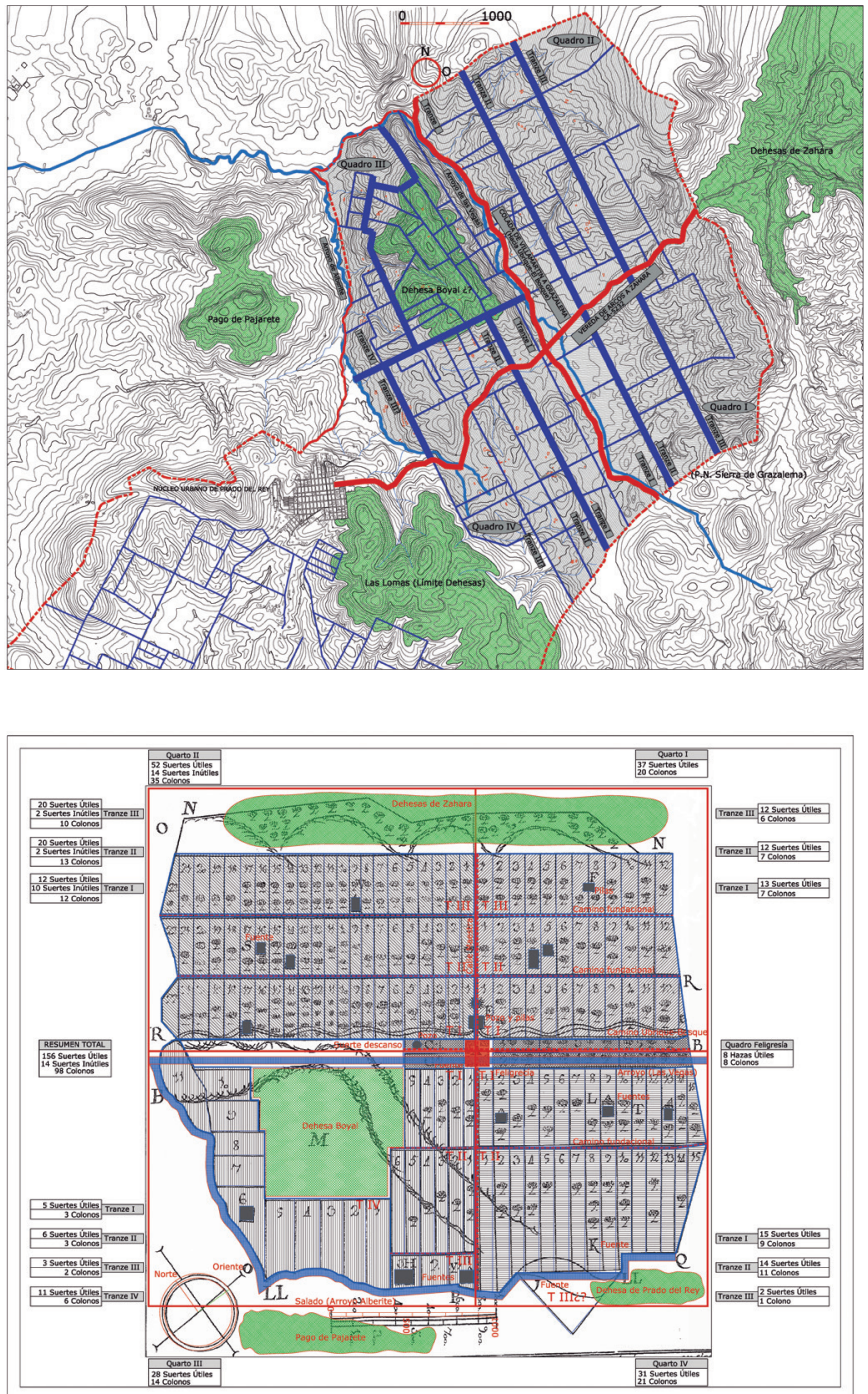
El estudio de caso lo enfocamos en la población andaluza de Prado del Rey por varios motivos: por ser un caso poco estudiado desde un punto de vista urbanístico; por su escala intermedia, que ayuda a generalizarla como elemento ejemplar de otras urbes coloniales; por sus características físicas y orográficas en tanto ejemplo de aplicación del urbanismo ilustrado colonial; por ser ejemplo de aplicación de los nuevos ideales y principios ilustrados de reforma económica y social en los conceptos de hábitat y ciudad en el siglo de oro; por sus condición actual, pues se preservan elementos a la vez que se analiza y proyecta su futuro urbano (Figura 9).

\section{Escala territorial}

La propia figura de planeamiento actual comporta el establecimiento de un modelo de ordenación que regule los procesos de renovación y ampliación de la estructura urbana actual a la vez que fija los criterios para la protección de los valores medioambientales y las medidas necesarias para su recuperación.

El proceso de ocupación del territorio de las nuevas poblaciones de colonización responde a una situación única en la cultura urbana y territorial, por lo que la salvaguarda y puesta en valor del modelo fundacional es una prioridad de cara a la futura redacción de sistemas de planeamiento y del territorio en estos núcleos (Figuras 10 y 11).

Para conocer la estructura territorial del estudio de caso, es muy importante analizar dos planimetrías que se realizaron en el año de 1768, es decir, antes de que comenzasen a llegar los primeros colonos. La importancia de estos dos planos radica en que son los únicos de todas las denominadas Nuevas Poblaciones que conocemos que se realizaron previamente a la propia colonización (Figuras 12 y 13).

Para el estudio de caso, se ha de establecer en su "Planeamiento General" (actualmente se encuentra en fase de exposición el nuevo Avance del P.G.O.U. de Prado del Rey, tras ser anulado por el Tribunal Superior de Justicia de Andalucía el anterior) las normativas de protección y puesta en valor para los elementos naturales, y para aquellos debidos a la acción del hombre:

\section{- Áreas aptas para cultivo}

- Áreas forestales, tanto de carácter denso como de matorral arbolado

- Cauces fluviales

- Vías pecuarias en todas sus categorías

- Parcelario histórico y elementos de deslinde

- Caminos fundacionales

- Protección y ordenación paisajística del suelo no urbanizable

- Previsión de varias figuras en el suelo urbano consolidado solo para completar sus límites

Debido a que parte de la Dehesa de Almajar pertenece al Parque Natural de la Sierra de Grazalema (los Quadros tercero y cuarto), está catalogada como "Zona de regulación especial B2 (Áreas de interés ganadero-forestal)", "Zona de regulación común C1 (Cultivos anuales en secano)" y "Zona de regulación común C2 (Olivares serranos)", y parte de la Dehesa de Prado del Rey se encuentra dentro del Parque Natural de los Alcornocales (cuarto Quadro y parte del primero), catalogada como"Zona de regulación especial B" y de "Regulación común C", actualmente se encuentran protegidas por los Planes de Ordenación de Recursos Naturales, y los Planes Rectores de Uso y Gestión de dichos parques, con competencias autonómicas y no locales.

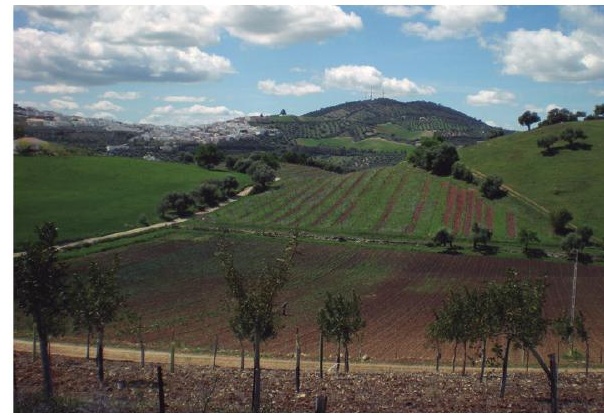

Figura 14. Dehesa de Almajar con caminos fundacionales y Prado del Rey al fondo

Fuente: Archivo fotográfico personal Carlos Quevedo, 2015.

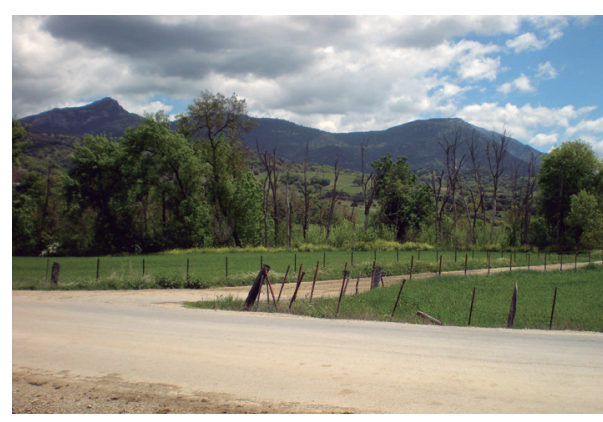

Figura 15. Cruce actual de caminos en la Dehesa de Almajar, donde se ubicaría la feligresía. Arroyo de las Vegas paralelo y Sierra de Grazalema al fondo

Fuente: Archivo fotográfico personal Carlos Quevedo, 2015.

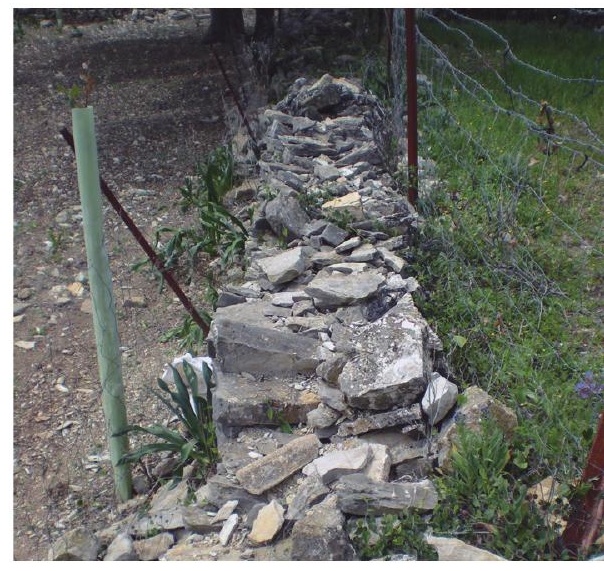

Figura 16. Vestigios de los pocos límites físicos de separación de suertes existentes realizados con fábrica de mampuestos irregulares

Fuente: Archivo fotográfico personal Carlos Quevedo, 2015. 
Aun así, la mayor parte de dichas dehesas no se encuentran en sendos parques, por lo que es el Plan General de Ordenación Urbana de Prado del Rey el que debe proteger dichas dehesas para intentar no alterar el uso, las parcelaciones, los recursos ni las infraestructuras que actualmente definen la política colonizadora llevada a cabo.

Es necesario desarrollar un planeamiento especial de protección para la sección de la Dehesa de Almajar que no se encuentra dentro del parque (como hábitats naturales de interés comunitario que establece el plan): con la categoría de 'Interés paisajístico' la franja central que discurre por el Arroyo de las Vegas, y de 'Bosque isla' y 'Matorral termomediterráneo' otras zonas de la Dehesa (Figuras 14, 15 y 16).

De igual forma ocurre en la Dehesa de Prado del Rey: en ambas quedan sin figura de protección las suertes repartidas por los primeros colonos, de las cuales queda todavía el trazado estructural.

Sin embargo, la Dehesa de Prado del Rey actualmente está más expuesta a las alteraciones paisajísticas y urbanísticas, por su cercanía a la carretera que va desde Arcos hacia la Sierra de Grazalema y el núcleo urbano que se ha ido consolidando durante los últimos años al pie de la Cabeza de Hortales.

Por tanto, sería aconsejable, como también lo recoge el propio Plan General, la creación de un Plan Especial que permita la salvaguarda de dichas dehesas y de su trazado originario, ya que se encuentran actualmente sin protección y sin una puesta en valor. Dicho plan protegería los valores del trazado (los trazos de cada cuarto) y subdivisiones de parcelas, así como los caminos fundacionales, elementos principales de interés, edificaciones originales, elementos singulares, y características del medio físico y natural.

De la misma forma, los 'Caminos rurales fundacionales' deben quedar protegidos, al igual que pasa con el resto de vías pecuarias, cañadas, etc. Se hace referencia en el planeamiento a las vías pecuarias, que quedan protegidas por su reglamento, pero no se cita las vías de acceso a las antiguas suertes dentro del parcelario original, que son de gran interés desde el punto de vista urbanístico. Además de la protección y salvaguarda, dicho plan recogería las medidas para una recuperación estructural de las dehesas en la medida de lo posible.

Otra figura de protección que se puede incoar de forma puntual es 'Lugar de Interés Etnológico', como se propone para el área de la Venta de la Parra, lugar de proyección de la feligresía de la Dehesa de Almajar, así como la catalogación patrimonial de las edificaciones originales (Figura 17).

La superposición de un trazado regulador a un complejo y variado espacio físico, como el de las dos dehesas originales, ha dado como resultado una peculiar distribución de itinerarios y localizaciones de las que aún se conservan suficientes vestigios que necesitan protección.

Al ser un ejemplo vivo de la política agraria y territorial de la llustración, los objetivos, desde un punto de vista territorial de protección, por tanto, pueden ser los siguientes:

- Protección del sistema hídrico y geológico que constituye un soporte óptimo para la biodiversidad de recursos naturales y valores ambientales independientemente de los que se incluyen en el Plan Rector de Uso y Gestión de los dos parques naturales

- Protección de los caminos fundacionales

- Medidas correctoras para paliar los impactos ambientales existentes y llevar a cabo la ordenación paisajística

De esta manera se garantiza la protección del parcelario fundacional, de los itinerarios históricos y del paisaje. 


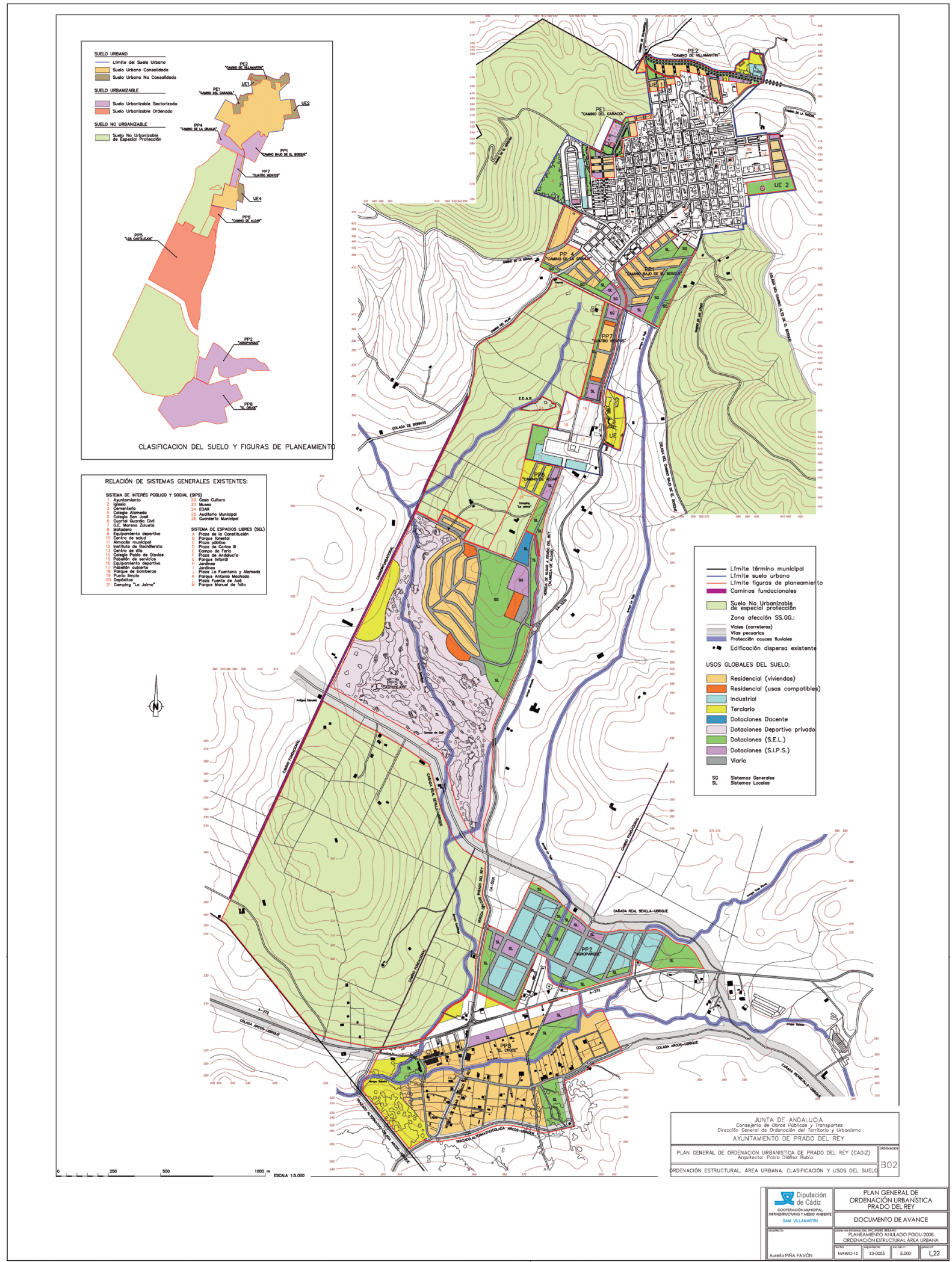

Figura 17. Plano de Ordenación del Avance del Plan General de Ordenación Urbana de Prado del Rey, 2006 Fuente: Ayuntamiento de Prado del Rey, 2006. 


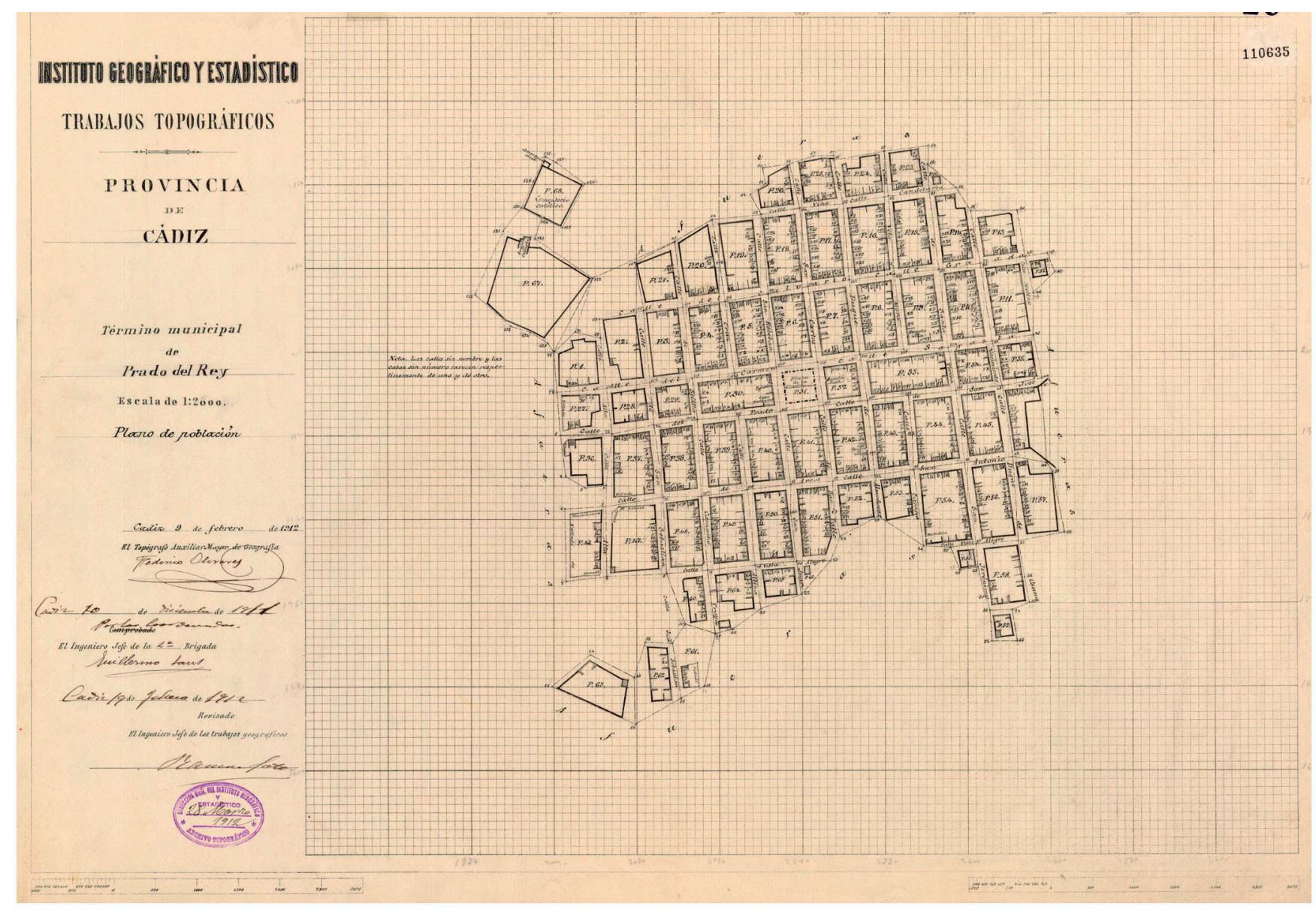

Figura 18. Término municipal de Prado del Rey

Fuente: Instituto Geográfico y Estadístico. Archivo del Instituto Geográfico Nacional. E/1:2000, 1912

\section{Escala urbana}

El proceso de ocupación del territorio de las Nuevas Poblaciones de colonización responde a una situación única en la cultura urbana y territorial de Andalucía, por lo que el primer objetivo genérico que se propone es la salvaguarda y puesta en valor del modelo fundacional.

En el estudio de caso, para una puesta en valor es fundamental reconocer el valor de la traza urbana y la hábil adaptación del caserío a las acusadas pendientes derivadas de la topografía. A ello se une la existencia de buen número de edificios originales o con escasas transformaciones (Figura 18).

Al ver la trama actual del núcleo de Prado del Rey, lo que más destaca es la perfección en la ejecución de la realización del entramado reticular a pesar de haberse ejecutado en un terreno con una abrupta orografía.

El núcleo originario de Prado del Rey y su trama reticular permanecen intactos. La evolución urbana del núcleo en el último medio siglo y, principalmente, en estos últimos años, ha sido clara: se ha llevado a cabo la colmatación y prolongación de la trama originaria, y se han realizado intervenciones específicas perimetrales (ensanches) que no siguen el esquema del núcleo original.

En el núcleo originario colonial, las propias calles invitan al movimiento, a la continua búsqueda con la intención de que el espacio sea continuo, no jerarquizado; que todas las casas sean iguales en su altura y en su composición, llevando la idea utópica ilustrada de igualdad y equidad para todos los habitantes a la práctica. Es el factor sorpresa el que descubre los espacios más importantes, como es la Plaza de la Constitución, el corazón del núcleo urbano; el poder es del pueblo. Es el propio espacio público el que invita a la estancia del pueblo, donde los principales edificios públicos se manifiestan en su esplendor. 
En esta plaza rectangular es posible apreciar la centralidad de la misma, pues todos sus laterales y sus cuatro esquinas están edificadas por las manzanas continuas cerradas, lo que hace destacar la centralidad de sí misma. Es una estrategia muy usada en el urbanismo barroco francés para que la propia perspectiva del usuario no se desvíe en las calles colindantes a la plaza, sino que enfoque su atención en el centro de la misma, donde normalmente se ubicaba la estatua del rey. En este caso, el centro queda figurado por una fuente, símbolo del poder del pueblo (Figura 19).

Bajo esta misma premisa, sigue el esquema original proyectado que segmenta la urbe en cuatro zonas a partir de la plaza como elemento central, y que, a su vez, divide en cuatro zonas el territorio en el que se sitúa, en coincidencia con los cambios de pendientes hacia las cuatro esquinas a partir de este espacio central.

La plaza, además de su componente y características como elemento espacial, tiene una vertiente funcional: funge como lugar de celebraciones, de reunión, de ocio y de congregación de la población. Es el 'espacio común' por excelencia, el espacio libre, estático, de la urbe. Y, por tanto, no solo por la formalidad y composición de los edificios más emblemáticos que limitan el espacio de la misma, sino porque además, estos dos (poder civil y religioso) deben tener una relación directa con el pueblo, que se encuentra simbólicamente en el centro.

Existen otros espacios libres apoyados en la misma retícula, que se van creando por la prolongación urbana de la trama, así como un aumento de superficie de espacios verdes necesario ante un aumento de la población original. Es el caso de la plaza de Carlos III, con dimensiones de 30×30 metros, que continúa el esquema en retícula y se crea además con una premisa higienista; se sitúa junto al mercado para la ventilación del mismo. Ambas plazas se establecen en la retícula como un vacío dentro de la colmatación edificatoria en la trama urbana.

Sin embargo, a pesar de lo que pueda aparentar la planta del núcleo urbano, la realidad física, los fuertes desniveles que existen en el asentamiento de la población, hace que las viviendas en Prado del Rey queden escalonadas a lo largo de sus calles. Allí es

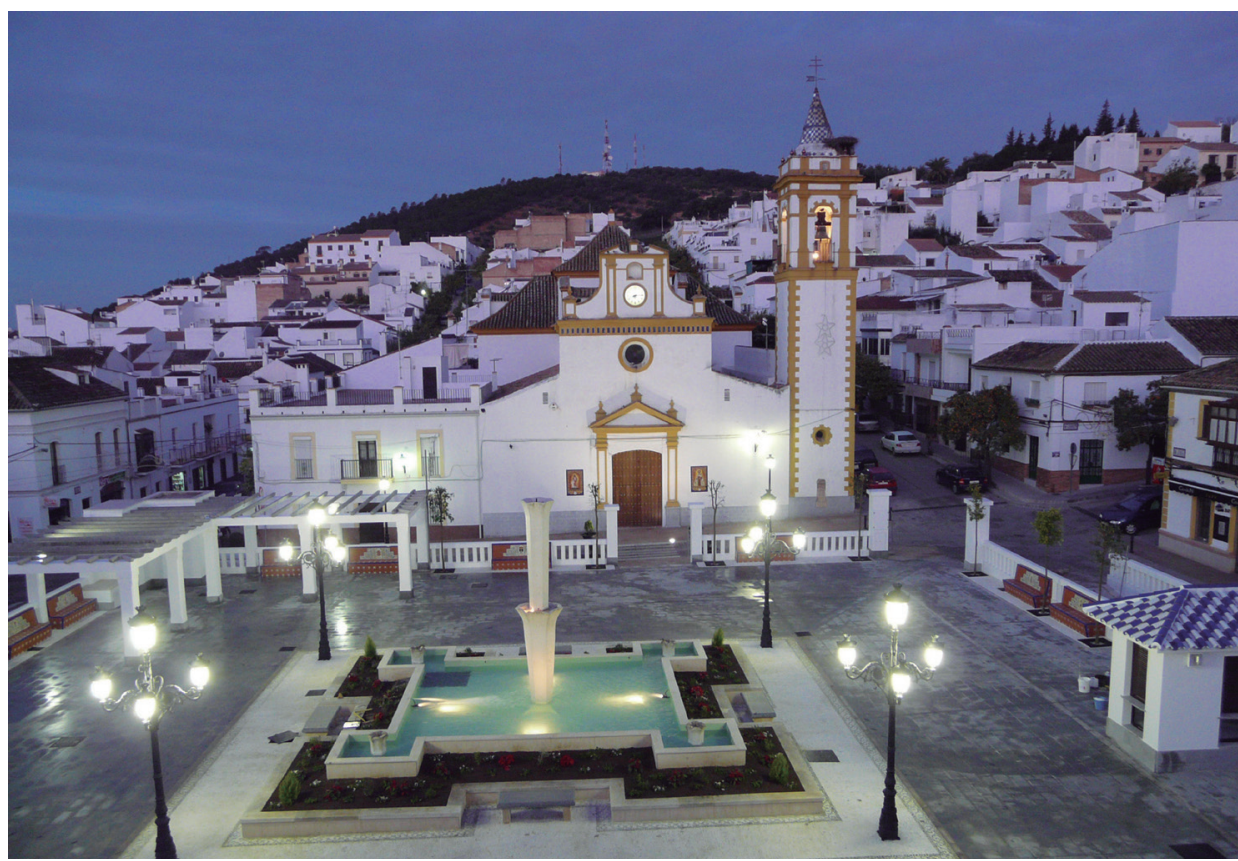

Figura 19. Vista actual Plaza de la Constitución de Prado del Rey

Fuente: Archivo fotográfico personal Carlos Quevedo, 2015. 
devenir Vol. 3, N6, JULIO-DICIEMBRE 2016, PP. 9-30 - EsTUdIOS I ISSN 2312-7570

UNIVERSIDAD NACIONAL DE INGENIERÍA, LIMA

Figura 20. Esquema de parcelaciones de las manzanas P.7 y P.33'

Fuente: Elaboración propia, 2016.

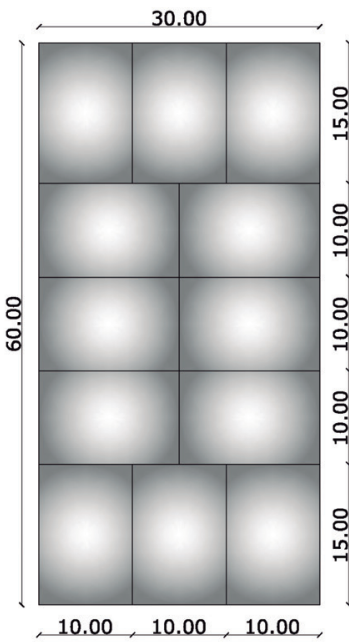

$\overbrace{}^{N}$

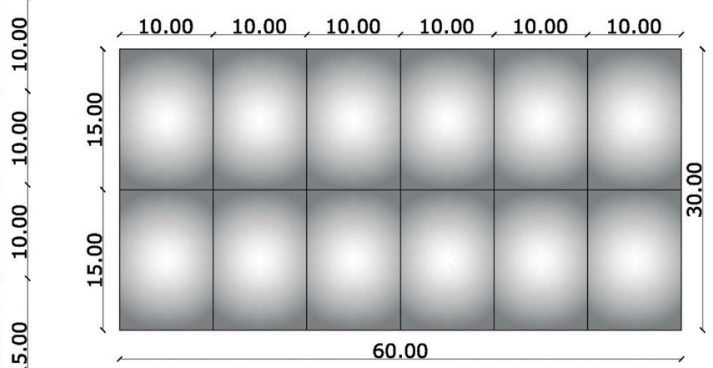

posible encontrar claros ejemplos de cómo la arquitectura popular es capaz de adaptarse al medio en el que se ubica, cómo el obrero fue capaz, con gran ingenio, de adaptar con los medios que le ofrecía la propia naturaleza la forma de la arquitectura a las circunstancias que se le iban imponiendo.

De este modo, debido a que la disposición del parcelario original era equitativo y las alturas de las viviendas eran constantes, es posible observar cómo en el núcleo originario las viviendas se van escalonando de manera uniforme a lo largo de sus calles, dentro de una composición racional y equitativa, cosa que no ocurre en el urbanismo de la periferia que se ha desarrollado durante los últimos años.

Se concibe una proporción armónica entre la altura de las viviendas y la anchura de las calles, lo cual garantiza su correcta ventilación y accesibilidad. Esas mismas calles, originariamente debido a los fuertes desniveles del terreno, tenían una pendiente en sentido transversal para garantizar también la evacuación de las aguas. Actualmente, con la aparición del tráfico motorizado, estas calles se desmontan para que la calzada quede horizontal, mientras que los acerados de acceso a las viviendas son de forma escalonada (Figura 20).

En cuanto a su conservación y tutela, es preciso realizar un catálogo de edificios y proponer como elemento a proteger el conjunto histórico. Para ello será necesario incoar el preceptivo expediente en el que se resalten los valores patrimoniales que encierra una de las más significativas acciones urbanísticas del periodo ilustrado en España.

El casco fundacional ha seguido un proceso de renovación muy limitado, pues, al tener establecidas las alineaciones, los usos y la volumetría como parámetros inalterables solo han sido objeto de nuevas construcciones en aquellos casos en los que la ruina legal de los inmuebles lo hacía inevitable.

En general, la normativa relativa al lenguaje arquitectónico de los edificios, así como la correspondiente a publicidad y tratamiento de los usos comerciales, ha permitido que la imagen urbana de la cuadrícula fundacional no se deteriore. No obstante, la valoración que se realiza sobre el buen estado de conservación de la estructura urbana se ha de articular con el entorno rural para el que fue proyectado.

Sin duda alguna es fácil reconocer los valores urbanísticos que posee la población. y que los objetivos que se desea cumplir son la mejora, puesta en valor, conservación y tutela. Sin embargo es necesaria la relación ciudad-territorio para que se refleje y no se 
olvide la idea básica a partir de la cual fueron proyectadas las colonias ilustradas como ejemplos de sociedad y de integración del hombre con la naturaleza.

Bien es cierto que es imposible que la sociedad y demandas actuales se puedan comparar con las experiencias de casi 250 años atrás, pero sí es posible realizar un planteamiento de intervención que respete las ideas básicas, o se haga conforme a un conocimiento e investigación de las mismas bajo un máximo respeto y estudio de lo preexistente como fase de análisis, diagnosis y estrategias previas a la propia intervención.

Se puede acometer, por tanto, no solo la protección del centro, sino la realización de un paquete de medidas correctoras sobre el desarrollo urbanístico sufrido en los últimos años en el área que se puede llamar 'ensanche'.

La mayor parte del daño que ha sufrido la zona de crecimiento o anillo de ensanche se debe a las intervenciones ocurridas desde finales del siglo XX hasta la actualidad. EI proceso de desarrollo urbanístico es irreversible y, por lo tanto, resulta muy difícil actuar en intervenciones ya ejecutadas; así, lo más viable su mejora a través de los Planes Especiales de Reforma Interior.

En tanto no se redacte un Plan Especial de Conjunto Histórico, las ordenanzas reguladoras del núcleo urbano serán las que rigen la salvaguarda de la imagen urbana propia del trazado fundacional, así como del interés paisajístico que el estudio de caso tiene por sus características orográficas concretas, tales como agregaciones y/o segregaciones, alturas máximas, tratamientos de las medianeras, tipos edificatorios, etc.

En tanto no se apruebe el Catálogo de Protección, se ha de considerar en el Planeamiento General el interés ambiental del núcleo histórico del estudio de caso para la preservación de la imagen urbana (Figura 21).

Por lo tanto, es requisito para la tutela del conjunto urbano la valoración pormenorizada de cada uno de los elementos que lo componen, con enfoque en la catalogación (ámbito arquitectónico), así como en los valores del propio conjunto de forma global, ya sean históricos, artísticos, arqueológicos, arquitectónicos, etnológicos, paisajísticos, etc.

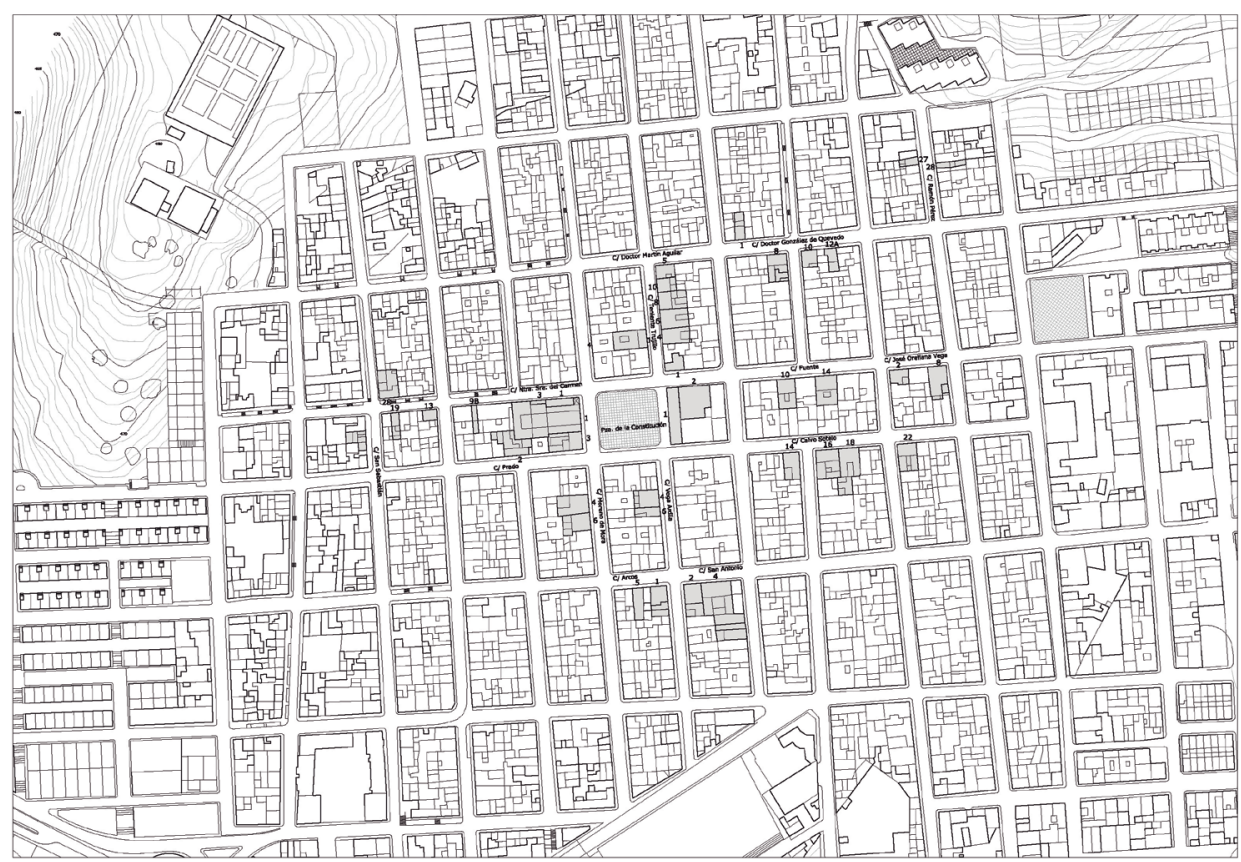

Figura 21. Propuesta de catálogo para el núcleo urbano

Fuente: Elaboración propia, 2016. 

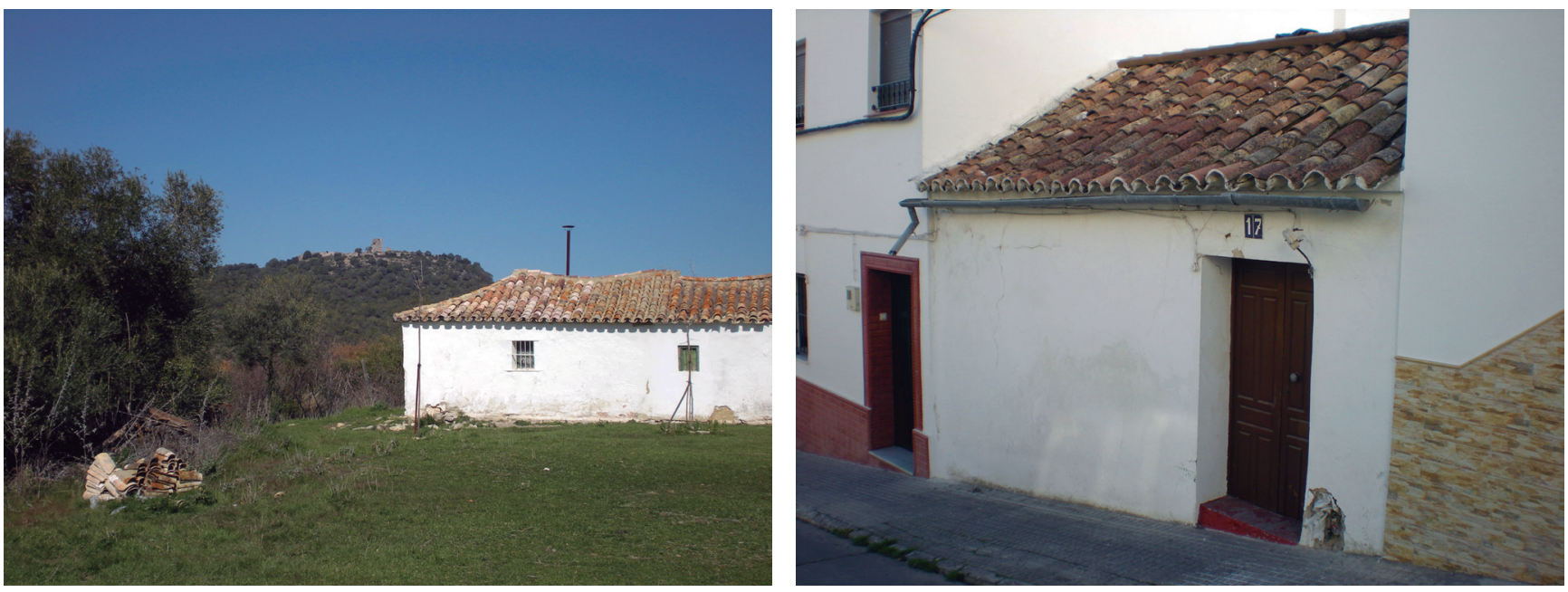

Figura 22. Arquitectura popular rural del estudio de caso

Fuente: Archivo fotográfico personal Carlos Quevedo, 2012.

Figura 23. Arquitectura popular urbana del estudio de caso

Fuente: Archivo fotográfico personal Carlos Quevedo, 2012.

Figura 24. Planta y sección de vivienda popular urbana

Fuente: Levantamiento realizado por Carlos Quevedo, 2012.

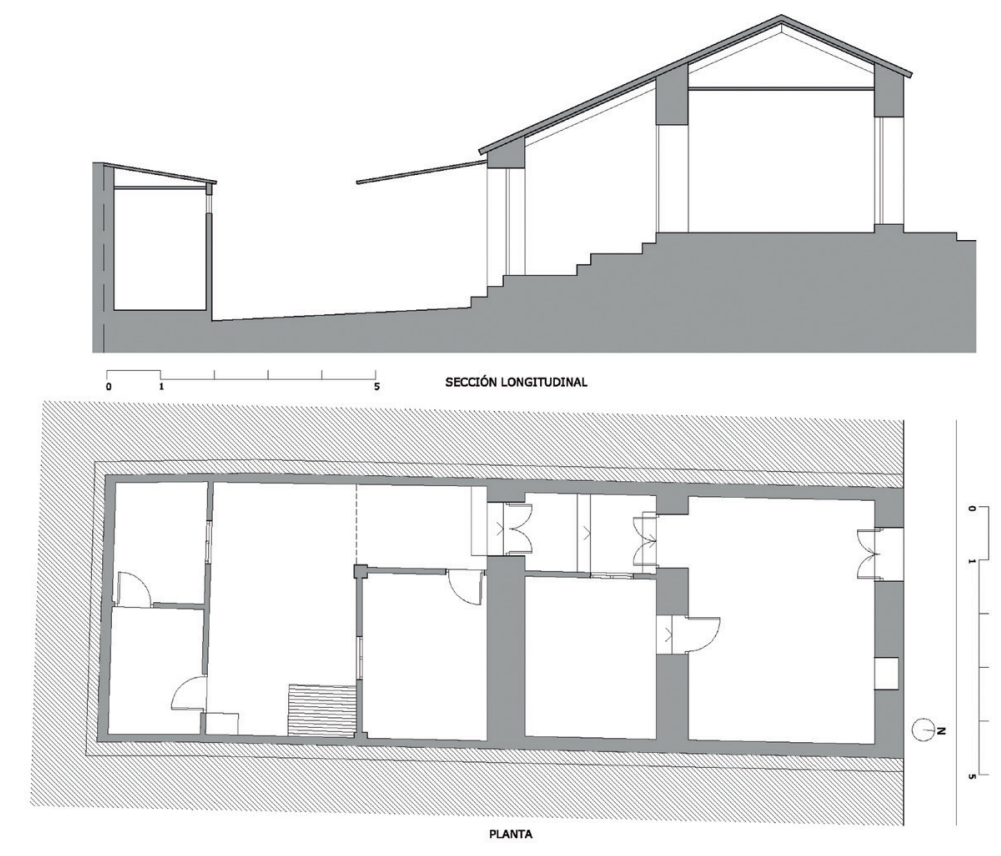

Para la tutela y salvaguarda del conjunto histórico el planeamiento especial debe tener en cuenta las siguientes consideraciones:

- Identificar las restricciones para cumplir los objetivos

- Analizar los factores ambientales

- Establecer medidas alternativas

- Elegir el método de actuación

- Catalogar los inmuebles y conjuntos urbanos de interés

- Redactar posibles ordenanzas que se ajusten a los objetivos planteados 
Se tendrán en cuenta los criterios básicos que afectan a la protección y mejora del conjunto, como la regulación de los tipos de intervenciones, la estructura urbana y de los espacios públicos; las condiciones y ordenanzas de las edificaciones, y sus usos; y la resolución de ciertos problemas funcionales y estéticos que afecten al mismo, para poder mejorar el mismo, y conservarlo para la integración en su entorno territorial de una manera sostenible y equilibrada.

\section{Escala arquitectónica}

Para plantear el análisis desde un punto de vista arquitectónico en el estudio de caso, se ha de tener en cuenta que el interés suscitado en nuestro ámbito de trabajo está relacionado directamente con la arquitectura rural. Las poblaciones no fueron realizadas por arquitectos profesionales, sino por personas que, siguiendo los patrones marcados por la experiencia y la tradición, construyeron con tierra y piedra las casas, chozas o establos hasta configurar una arquitectura que suscita un gran interés.

La arquitectura popular que conforma estas poblaciones se caracteriza por su adaptación al entorno que ocupa; queda señalada en el paisaje a lo largo de la historia como proceso de humanización, de arraigamiento del hombre en la tierra hasta a formar parte inseparable de la misma. Los espacios austeros y las construcciones sobrias son las que caracterizan a este tipo de arquitectura donde la funcionalidad es el alma de la edificación.

La explotación agraria es donde mejor se puede observar la simbiosis hombre-lugar-arquitectura, sin dejar a un lado la cultura o la sociedad en la que se desarrolla, ya que son factores innatos que siempre están presentes, independientemente del lugar en cuestión.

En general, la composición de los poblados, como la jerarquización de las calles y de los espacios interiores de los edificios, corresponde a modelos estrictos, resultado de leyes socioculturales, el clima y la tecnología disponible.

Se trata, por tanto, de un caso en el que la edificación está vinculada a la propia política de implantación en el territorio. Se trata del llamado'modelo disperso intercalar', que implica dispersión de casas a partir de un primitivo núcleo concentrado, que se desarrolla principalmente por el deseo de explotar nuevas tierras o el propio monte. Las casas siguen teniendo relaciones con los núcleos concentrados de tipo religioso (parroquia), económico (mercado y pósito), social y administrativo (ayuntamiento) (Figuras 22, 23 y 24).

En lo que respecta al diagnóstico en los ámbitos territoriales y urbanos de estas poblaciones de colonización, es en este hábitat rural donde se aprecia una serie de valores arquitectónicos, etnológicos, paisajísticos, monumentales, históricos y culturales que se deben de identificar y conservar, ya que dichos valores son los representantes de la población como pueblo y sociedad.

$Y$ es que existe una degradación del sector rural actual en cuanto a su función original como uso agropecuario, en parte debido al avance tecnológico que hace que el hombre abandone el hábitat rural para trasladarse al urbano. Así, uno de los sectores menos conocido y valorado del patrimonio monumental de Andalucía es la arquitectura rural. La pérdida, en la mayoría de los casos, de la funcionalidad original de los edificios y el abandono progresivo por una población rural declinante ha provocado que su destino resulte incierto en la actualidad. Debido a este abandono, han ido colapsando en el medio rural muchas de estas edificaciones; se encuentran en un pésimo, en ruinas en su mayoría, o se están reconstruyendo para satisfacer la cada vez mayor demanda de turismo rural.

Por tanto, se debe no solo valorar este patrimonio rural, sino aprender del mismo, ya que son las técnicas no solo constructivas, sino de elaboración de los propios ingenios y funcionalidad en este hábitat, las que se han ido desarrollando a lo largo de los años 
por la propia experiencia del hombre, por lo que es crucial conservar dicho patrimonio, una fuerte tradición empírica a la que no se puede dar la espalda, sino aprender de ella.

Ante estas construcciones, existen muchísimas soluciones para un mismo problema, xtodas ellas basadas en lo mismo: la eficacia y la sobriedad. También se siente esa intemporalidad de algo que permanece. Nuestro deber es no solo la investigación orientada a conocer todo este patrimonio rural, sino el poder aplicar dichos conocimientos a la conservación y protección del mismo, así como a nuestra arquitectura y tecnología actual.

Para la tutela y salvaguarda de esta arquitectura rural diseminada y popular urbana, serían las propias figuras de planeamiento propuestas en los artículos precedentes las que impondrían las bases de intervención a partir de un estudio detallado de las mismas. Un Plan Especial de Protección, o incluso la figura de protección 'Zona Patrimonial', recogida en la Ley de Patrimonio Histórico de Andalucía (Ley 14/2007, 26 de noviembre), siguiendo como ejemplo el estudio de caso, sería recomendable para las, dehesas de Almajar y Prado del Rey, por la variedad de valores culturales que poseen, además de un Plan Especial de Conjunto Histórico para el núcleo urbano de Prado del Rey.

Con respecto a este último punto, sería un catálogo el que haría referencia a las posibles intervenciones a realizar de manera individualizada en cada edificación del núcleo tradicional de Prado del Rey. Dicho catálogo de la nueva figura de planeamiento ha de recoger la totalidad de edificaciones privadas populares, así como los edificios de carácter público de interés, para su protección y tutela.

La metodología a seguir para la redacción del catálogo de bienes inmuebles sería la siguiente:

- Etapa de selección previa

- Selección de los edificios declarados, incoados o de interés

- Preselección de las edificaciones y los ámbitos que por su significación externa caracterizan al conjunto

- Operar con elementos constructivos y ornamentales, y ámbitos de interés

- Etapa de catalogación en función de una valoración específica relativa a las características de cada espacio o edificio

- Valor histórico

- Valor arquitectónico: definido por el interés tipológico percibido; la escala, forma y proporción; el material, color y texturas; y los elementos constructivos y ornamentales que posee cada conjunto o edificio

- Valor urbano: la significación de cada espacio o edificio en relación con la calle, espacios libres, etc.

- Características de conservación

- Carácter funcional: implica cuantificar la adaptación funcional de lo catalogado de acuerdo a su habitabilidad, adecuación al uso original y al entorno, y estructura de la propiedad

- Carácter cultural: la importancia cultural del bien catalogado

- Carácter paisajístico: la contribución al paisaje y al medioambiente

- Etapa de otorgamiento de los grados de protección aplicables 
Tras las dos etapas anteriores, efectuada la asignación de categorías, se procedería a establecer los niveles de protección considerados, que pueden ser los siguientes:

- Protección integral

- Protección estructural

- Protección ambiental

- Protección de espacios y elementos urbanos

- Protección de las zonas arqueológicas

- Resto de edificaciones a ser incluidas en el Conjunto Histórico y su entorno

- Elementos o edificaciones fuera de ordenación

Se propone un inventario de edificaciones conforme a los valores establecidos en la etapa previa tras un análisis de sus características estéticas, constructivas, históricas y etnológicas.

Es importante destacar también la protección y el catálogo de edificaciones que se encuentran en el hábitat rural de las dos dehesas, de gran importancia y conocimiento por su carácter etnológico y paisajístico, que han de acometerse dentro de sus respectivas figuras de protección tras su inclusión en el inventario.

También ha de considerarse el control, como medida preventiva, de realización de construcciones no vinculadas con la actividad agropecuaria que se está produciendo en dichas dehesas con un claro impacto negativo en el paisaje.

\section{Conclusiones}

De alguna forma se refleja la influencia que la experiencia urbanizadora llevada a cabo en América por los conquistadores españoles tuvo; esta sirvió como precedente en varios aspectos para la configuración física de posteriores e incluso coetáneas intervenciones urbanas realizadas en la península.

Como vemos en el caso de las Nuevas Poblaciones de Colonización en Sierra Morena y Andalucía, brillante ejemplo del urbanismo en España durante la llustración, dichas experiencias urbanizadoras, el origen criollo de su promotor, y las ordenanzas e instrucciones previas que marcaban las directrices de ocupación del territorio son claros ejemplos de la fuerte influencia americana sobre las urbes peninsulares.

De la misma forma hemos podido observar una respuesta recíproca, como continuidad de un diálogo llevado a través del Atlántico a lo largo de toda la época moderna, el cual ha establecido, dentro del complejo sistema o entramado que conforma la ciudad, nexos de unión que ya forman parte de una cultura e identidad propia de las urbes hispanoamericanas.

Al igual que en las colonias hispanoamericanas, en Andalucía también se llevó a cabo una 'colonización' por castellanos, al menos ideológica y política, y una estructuración productiva de subsistencia para la gran mayoría. Ambos lados del Atlántico comparten en este sentido una cultura urbana común.

Se constata de esta forma una preexistencia de trazado, como la trama en cuadrícula hispanoamericana que, durante su evolución, se fue modificando para cualificar los espacios urbanos; dicha evolución, fluyó de manera diversa según el contexto histórico en cada caso concreto, lo que dota de una identidad propia a cada ciudad, que se refleja en un carácter local que comparte una base común. 
Las sociedades dependientes, yuxtaposiciones culturales y aspectos climáticos no son sino fragmentos de un complejo mosaico que caracteriza a las ilaciones iberoamericanas. No solamente se ha de pensar en la configuración física del espacio urbano, sino en la manifestación conceptual de una organización abstracta que prolongue hacia el exterior la reflexión y la conceptualización realizada sobre el espacio urbano, lo que Fernando de Terán llamaba "sueño de un orden" (Terán, 1985, p. 34).

Por tanto, a pesar de plantear en cada caso, independientemente de su ubicación geográfica, las pautas para la conservación, tutela y puesta en valor del patrimonio urbano colonial existente, estas pueden y deben tener algunos criterios comunes en las diversas escalas de trabajo: territorial, urbano y arquitectónico. Las herramientas jurídicas en cada país y región, dependiendo de sus competencias administrativas en el ámbito cultural y urbanístico, deben establecer reglamentos para cada caso específico bajo estas pautas comunes con el fin de poder gestionar y llevar a cabo una política de conservación de este importante patrimonio construido.

\section{Referencias}

Benévolo, L. (1979). Orígenes del urbanismo moderno. Madrid, España: Celeste.

Capel Margarito, M. (2000). Don Pablo de Olavide: un criollo, amigo de Jovellanos, en el equipo reformista de Carlos III. Jaén, España: Colección Semilla y Flor.

Chueca Goitia, F. (1970). Breve historia del urbanismo. Madrid, España: Alianza Editorial.

Guamán Poma de Ayala, F. (s. XVI). Nueva corónica y buen gobierno (Ed. facsímil, 1989). París, Francia: Institut d'ethnologie.

Gutiérres, R. et al. (1995). Andalucía en América: el legado de ultramar. Barcelona, España: Sierra Nevada '95 - El Legado Andalusí- Lunwerg.

Hardoy, J. E. (1972). El modelo clásico de la Ciudad Colonial Hispanoamericana: un ensayo sobre la legislación urbana y la política urbana de España en América durante las primeras décadas del periodo colonial. En Actas del Congreso XXXVIII de Americanistas (pp. 45-52). Buenos Aires, Argentina: Centro de Estudios Urbanos y Regionales, Instituto Di Tella.

Heffes, G. 2013. Utopías urbanas: geopolíticas del deseo en América Latina. Madrid, España: Iberoamericana.

Lohmann, G. (1974). Los ministros de la Audiencia de Lima (1700-1821). Sevilla, España: Escuela de Estudios Hispanoamericanos.

Marchena Fernández, J. (2001). El tiempo ilustrado de Pablo de Olavide: vida, obra y sueños de un americano en la España del s. XVIII. Sevilla, España: Alfar.

Mattos-Cárdenas, L. (1987). Olavide y el Urbanismo. En Actas de las VII Jornadas de Andalucía y América (pp. 109-140). Sevilla, España: Escuela de Estudios Hispano-Americanos de Sevilla.

Mattos-Cárdenas, L. (2004). Urbanismo andino e hispano americano: ideas y realizaciones (15301830). Lima, Perú: Facultad de Arquitectura, Urbanismo y Artes de la Universidad Nacional de Ingeniería.

Musset, A. et al. (1997). De Séville à Lima: Villes en paralele. París, España: Université de Paris X Nanterre Laboratoire de Géographie Urbaine.

Terán Troyano, F. de. (1985). Centralismo y descentralización. Modelos y procesos históricos en Francia y España. Madrid, España: IEAL.

Terán, F. de. (2001). El urbanismo en el Nuevo Mundo: el ejemplo peruano. Lima, Perú: Centro Cultural de España. 